\title{
Towards Multipotent Coatings: Chemical Vapor Deposition and Biofunctionalization of Carbonyl-Substituted Copolymers
}

\author{
Yaseen Elkasabi, Mutsumi Yoshida, Himabindu Nandivada, \\ Hsien-Yeh Chen, Joerg Lahann*
}

Future advances in designing bioactive materials, such as antithrombotic coatings for cardiovascular stents, will require widely applicable and robust methods of surface modification. In this paper, we report on the development of multifunctional polymer coatings made by chemical vapor deposition (CVD) copolymerization. Polymer coatings of various [2.2]paracyclophane derivatives were co-deposited in controlled ratios and their chemical composition verified by FT-IR and X-ray photoelectron spectroscopy. Furthermore, preliminary biocompatibility of these coatings was assessed using human umbilical vein endothelial cells and 3T3 murine fibroblasts. The parallel immobilization of two different antithrombotic biomolecules onto a CVD-based copolymer is also demonstrated by orthogonal immobilization strategies.

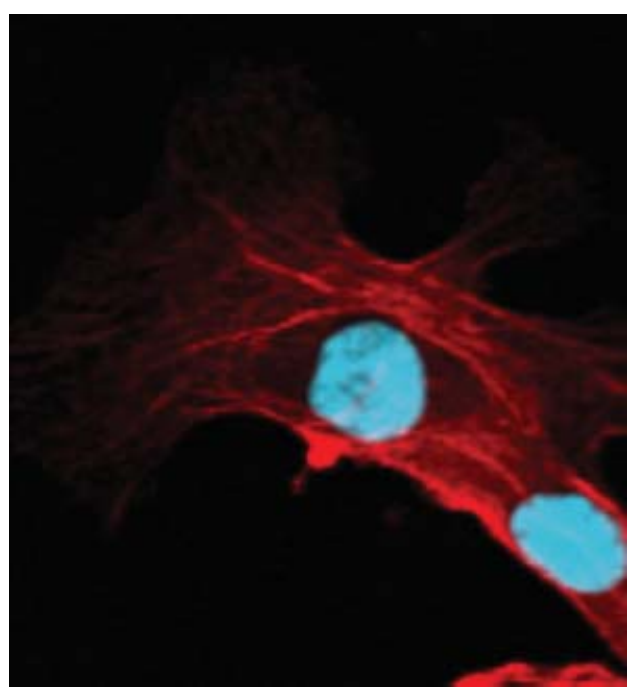

\section{Introduction}

The fields of materials engineering and biointerface science are witnessing an increasing merger of concepts and applications. ${ }^{[1]}$ While these two fields remained quite exclusive from each other only 40 to 50 years ago, ${ }^{[2]}$ recent progress in biotechnological and medical applications has expedited and necessitated their fusion. Examples include, but are not limited to, the study of cell/matrix interac-

Y. Elkasabi, M. Yoshida, H. Nandivada, H.-Y. Chen, J. Lahann Departments of Chemical Engineering, Materials Science and Engineering, and Macromolecular Science and Engineering, University of Michigan, Ann Arbor, 48109, USA

Fax: (734) 764-7453;

E-mail: lahann@umich.edu tions, ${ }^{[3]}$ micro total analytical systems $(\mu \mathrm{TAS}),{ }^{[4]}$ and scaffolds for tissue engineering. ${ }^{[5]}$ More specifically, these applications require materials with sufficient mechanical integrity, while providing adequate contact properties within biologically relevant environments. To date, many of the currently employed biomaterials still induce unfavorable responses, such as chronic inflammation ${ }^{[6]}$ or blood coagulation. ${ }^{[7,8]}$ One way of addressing these shortcomings is controlled surface modification, because interactions of the biomaterial surface with proteins and cells are among the key factors that govern these biological responses. ${ }^{[8,9]}$ Methods such as plasma polymerization, ${ }^{[10]}$ self-assembly of monolayers, ${ }^{[11]}$ and spray coating ${ }^{[12]}$ have been extensively used in the past to design materials that exhibit defined surface chemistries; however, many of these methods fall short when devices with materials that 


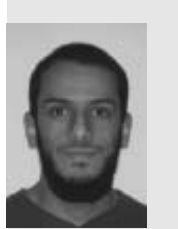

Yaseen Elkasabi is currently a Ph.D candidate in the Department of Chemical Engineering at the University of Michigan. He received his M.Sc. in Chemical Engineering from the University of Michigan in 2006 and a B.Sc. in Chemical Engineering from Michigan State University in 2004. Yaseen's current research interests include synthesis of multifunctional polymer coatings by chemical vapor deposition copolymerization.

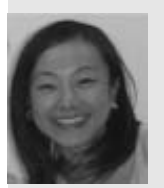

Mutsumi Yoshida received her Ph.D. in Biomedical Engineering from Georgia Institute of Technology and Emory University in 2005 under the guidance of Prof. J. Babensee. She is currently a postdoctoral research fellow at the University of Michigan in the Department of Chemical Engineering. Her current research interests include cellular responses at materials interfaces.

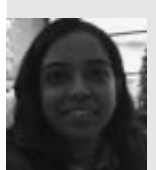

Himabindu Nandivada is pursuing her Ph.D in the Department of Chemical Engineering at University of Michigan. She obtained her M.Sc. in Chemical Engineering from the University of Michigan in 2005 and a B.Tech. in Chemical Engineering from the Indian Institute of Technology, Kanpur in 2003. Her current research interests include developing immobilization strategies for designing biofunctional surfaces via reactive coatings.

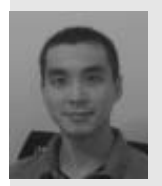

Hsien-Yeh Chen received his Ph.D. in Chemical Engineering from the University of Michigan in 2007. He obtained his M.Sc. in Chemical Engineering from the University of Michigan in 2004 and a B.Sc. in Chemical Engineering from the National Taiwan University in 1999. His research interests include surface engineering of microfabricated devices using chemical vapor deposition polymerization. Hsien-Yeh is currently a research scientist with AST Products, Inc.

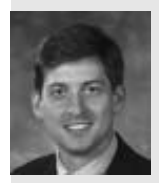

Joerg Lahann is the Dow Corning Assistant Professor in Chemical Engineering at the University of Michigan. His research interest is focused on the development of synthetic strategies that bring together concepts from materials science and biotechnology. He recieved a Ph.D. from the RWTH Aachen, Germany, in Macromolecular Chemistry under the guidance of Prof. H. Hoecker. After working as a postdoctoral researcher with Prof. R. Langer at the Massachusetts Institute of Technology, he joined the departments of Chemical Engineering, Materials Science and Engineering, and Macromolecular Engineering at the University of Michigan in 2003. Joerg Lahann has been selected by Technology Review magazine as one of the top 100 young innovators with the greatest potential to have an impact on technology in the 21st century. He is also a recipient of the 2006 DOD Idea award, the 2007 NSEF Award of the AICHE, and a NSF-CAREER award. He is co-author of more than 60 publications and the inventor or co-inventor of more than 20 patents or patent applications.

diverge from well-defined model systems and non-planar geometry are used. ${ }^{[13]}$ Although widely used, solutionbased surface modification methods bear the risk of introducing coating non-uniformities and impurities. ${ }^{[14]}$ In addition to the large number of solvent-based methods used for biomedical surface modification, solventless surface modification methods, such as chemical vapor deposition (CVD) polymerization, have increasingly been explored for biomedical coatings. CVD polymerization offers several unique advantages as compared to other solvent-based coating processes. First, CVD coatings are conformal, which allows for easy and uniform modification of non-planar substrate geometries. ${ }^{[15]}$ Second, although the activation step (which takes place away from the substrate) requires high temperatures, the substrates can be maintained at a controlled temperature - typically room temperature, or below. Third, impurities associated with the use of solvents, initiators, or plasticizers can be precluded. Several examples of CVD-based polymer coatings have been reported: Frank and coworkers ${ }^{[16]}$ have used CVD to prepare polypeptide chains that are grafted onto a surface, and Gleason and coworkers have shown through various examples ${ }^{[17]}$ that, even if the monomer of interest does not contain an initiator, polymerization initiators can be introduced together with the monomer through basic process modification. In cases where hot filaments within the deposition chamber were used for initiation, radical polymerizations often yielded conformal coatings. Patterning the surface with the initiator ${ }^{[18]}$ has been shown to result in microstructured polymers, a method useful for fabricating micrometer-scale devices.

The focus of our group in this area has been on CVD polymerization of substituted [2.2]paracyclophanes (PCP) to yield functionalized poly ( $p$-xylylenes) (PPX). This CVD polymerization is adapted from a process first developed by Gorham for parylene coatings. ${ }^{[19]}$ In this procedure (Scheme 1), a cyclic dimer is sublimated under vacuum 
(0.2-0.3 Torr), and transported by a carrier gas through an external heat source $\left(T=600-800^{\circ} \mathrm{C}\right)$. When the temperature is high enough, a homolytic cleavage occurs across both bridge bonds, which results in two quinodimethane diradicals. The radicals then deposit and polymerize onto a sample that is fixed at a particular temperature (between -40 and $60^{\circ} \mathrm{C}$ ). We have successfully modified PCPs with a wide variety of functional groups, ${ }^{[20]}$ which can then serve as reactive sites for immobilization of biomolecules. Polymerization of PCPs produces a conformal PPX coating with mechanical integrity and low dielectric constants, which are useful attributes for various applications including microelectromechanical system (MEMS) devices. $^{[21]}$

A heterogeneous group of functionalized polymer coatings can be synthesized from substituted PCPs (Scheme 2). Carbonyl-functionalized polymers establish an interesting subclass that our group has utilized in various applications. In particular, we have taken advantage of the photo-reactivity of the benzoyl-functionalized polymers. ${ }^{[22]}$ In addition, aldehyde-functionalized PCPs have been successfully polymerized, while maintaining a high reactivity of the functional groups, as shown by immobilization of disaccharides onto the resultant poly-

(a)

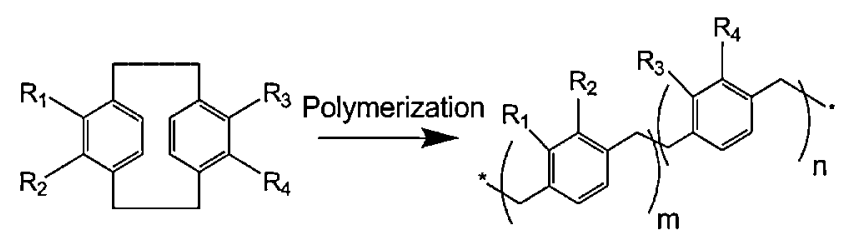

(b)

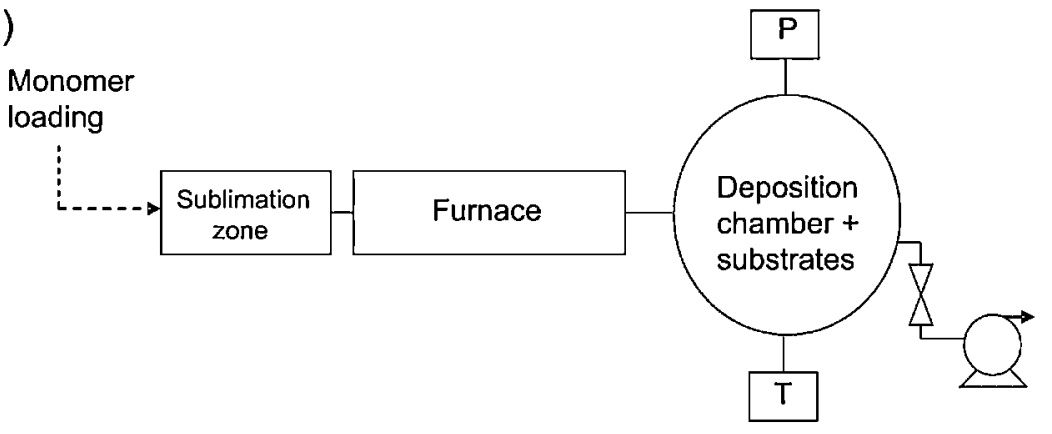

(c)<smiles>O=CC1CC2CCC3CCC(C1)C32</smiles><smiles>CC(C)(Br)C(=O)OCC1CC2CCC3CCC(CCC31)C2</smiles><smiles>O=C(O)C(=O)OCC1CC2CCC3CCC(CCC31)C2</smiles><smiles>CS(=O)(=O)OCC1CC2CCC3CCC(C1)C3CC2</smiles><smiles>NCC1CCCC2CCC3CCC(CC3)C2C1</smiles><smiles>NC1CC2CCC(CC2)C(N)C1</smiles><smiles>Nc1ccccc1-c1ccc2ccccc2c1</smiles><smiles>C#CC1CC2CCCC(C1)C2</smiles><smiles>OCC1=CC2CCC3CCC(CCC3CC2)C1</smiles><smiles>COCC1=CCC2CCC3CCCC(CC3)C2C1</smiles>

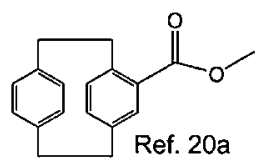<smiles></smiles>

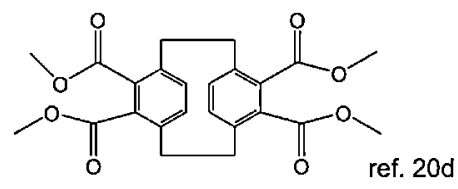

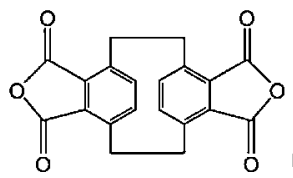
ref. $20 \mathrm{~d}$

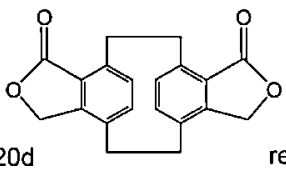

ref. $20 \mathrm{a}$

Scheme 1. a) Functionalized [2.2]paracyclophanes (PCPs) are polymerized into poly( $p$-xylylenes) (PPXs) with tailored reactivity, which are deposited as thin films. b) Process scheme for the chemical vapor deposition (CVD) of PPX. c) Various derivatives of PCP have been synthesized for use in CVD polymerization. 
(a)

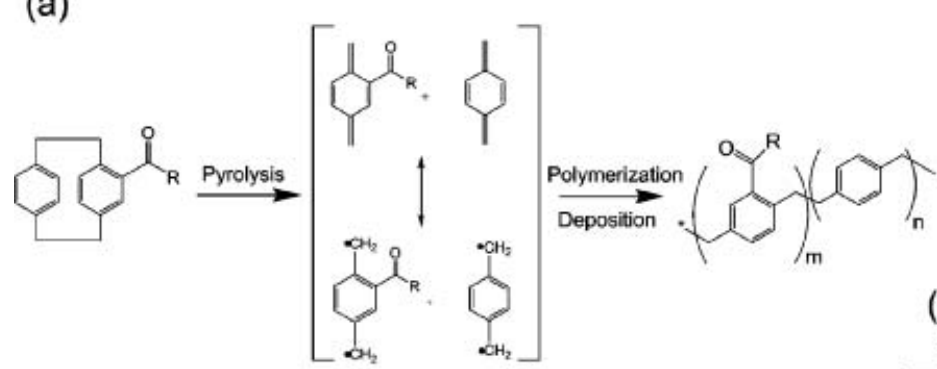

(c)

\begin{tabular}{c|c|c|c|c}
$\mathrm{R}=$ & $\mathrm{T}_{\text {sub }}\left({ }^{\circ} \mathrm{C}\right)$ & $\mathrm{T}_{1}\left({ }^{\circ} \mathrm{C}\right)$ & $\mathrm{T}_{2}\left({ }^{\circ} \mathrm{C}\right)$ & $\mathrm{T}_{\text {prr }}\left({ }^{\circ} \mathrm{C}\right)$ \\
\hline $\mathrm{C}_{6} \mathrm{H}_{5}$ & 110 & 685 & 800 & 810 \\
$\mathrm{C}_{2} \mathrm{H}_{5}$ & 80 & 555 & 660 & 670 \\
$\mathrm{C}_{2} \mathrm{~F}_{5}$ & 75 & 540 & 660 & 670 \\
$\mathrm{CF}_{3}$ & 80 & 555 & 660 & 670
\end{tabular}

(b)

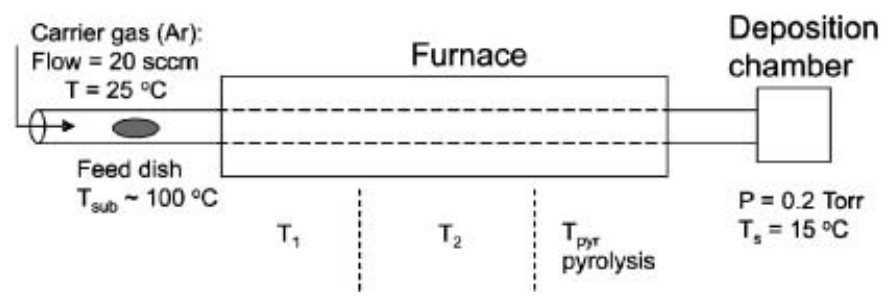

Scheme 2. a) Mechanism for the CVD polymerization of carbonyl-functionalized PCPs to produce corresponding PPXs. b) Schematic diagram of the CVD process. c) CVD process conditions required for PPX deposition.

mer coating. ${ }^{[23]}$ Once a suitable, defined, and biocompatible surface modification strategy has been established for a given biomedical device, imparting complexity, such as immobilization of multiple biomolecules, becomes another key issue. For example, an ideal endovascular stent would promote endothelial tissue growth, while preventing thrombogenicity. ${ }^{[24]}$ Biological interactions are hardly ever monovalent and typically involve a complex cascade of activating and inhibitory signals. Yet, almost all synthetic surface modification concepts rely on a single type of surface cue, i.e., immobilized peptides, proteins, or antibodies. One of the reasons for this highly reductive approach is because of the technical difficulty in achieving controlled, simultaneous presentation of two or more biomolecules. Such a procedure demands precise control of multiple surface reactions, while avoiding crossreactivity between the different chemical groups. ${ }^{[25]}$ This issue has posed a significant challenge to the field

More recently, our group has started to explore new avenues to address this challenge by developing multivalent surface coatings using CVD copolymerization. Using this approach, we have been able to copolymerize two different PCPs with orthogonal reactivities. We further demonstrated that the resulting coatings can be used to immobilize multiple biomolecules in defined ratios. ${ }^{[26]}$ In this contribution, we focus on the synthesis and characterization of carbonyl-functionalized copolymers and elucidate important aspects of these coatings for future biomedical applications. Scheme 3 illustrates the CVD copolymerization mechanism for carbonyl-functionalized polymer coatings.

\section{Experimental Part}

\section{Monomer Synthesis}

4-Aminomethyl-[2.2]paracyclophane was purchased from Uniglobe Kisco, Inc. (White Plains, NY). 4-Amino-[2.2]paracyclophane was synthesized from [2.2]paracyclophane using an established synthesis route. ${ }^{[27]}$ All carbonyl-functionalized PCPs were synthesized by Friedel-Crafts acylation of commercially available [2.2]paracyclophane (Uniglobe Kisco) as described previously. ${ }^{[20]}$ All synthesized monomers were purified by column chromatography prior to CVD polymerization, and characterized by NMR spectroscopy, mass spectrometry (MS), and FT-IR spectroscopy.

\section{CVD Polymerization}

All polymer coatings were synthesized using a custom-built CVD system. ${ }^{[28]}$ For CVD polymerization, a total of 20-30 mg of either one or two different functionalized [2.2]paracyclophane(s) was used. For copolymerization, the molar ratios of aminofunctionalized $\left(-\mathrm{NH}_{2},-\mathrm{CH}_{2} \mathrm{NH}_{2}\right)$ and carbonyl-functionalized $\left(-\mathrm{COC}_{6} \mathrm{H}_{5},-\mathrm{COC}_{2} \mathrm{H}_{5},-\mathrm{COC}_{2} \mathrm{~F}_{5},-\mathrm{COCF}_{3}\right.$ ) PCPs (refer to Scheme 3) were varied to yield a previously specified target ratio of functional groups of the CVD coatings. To account for differences in the sublimation temperatures of different PCPs, charges of starting material were loaded individually into magnetically movable glass dishes. For CVD copolymerization, the working pressure was 0.28 Torr and sublimation temperatures varied between 90 and $100{ }^{\circ} \mathrm{C}$. For different functionalized PCPs, the pyrolysis temperature changed with various functionalities. $\mathrm{PCP}-\mathrm{COC}_{6} \mathrm{H}_{5}$ was activated at a pyrolysis temperature of $800^{\circ} \mathrm{C}$ in order for polymerization to occur, whereas all other monomers were cleaved at $670^{\circ} \mathrm{C}$. Preparation of copolymers $\left(-\mathrm{COC}_{6} \mathrm{H}_{5} /-\mathrm{NH}_{2}\right.$ and $-\mathrm{COC}_{6} \mathrm{H}_{5} /-$ 


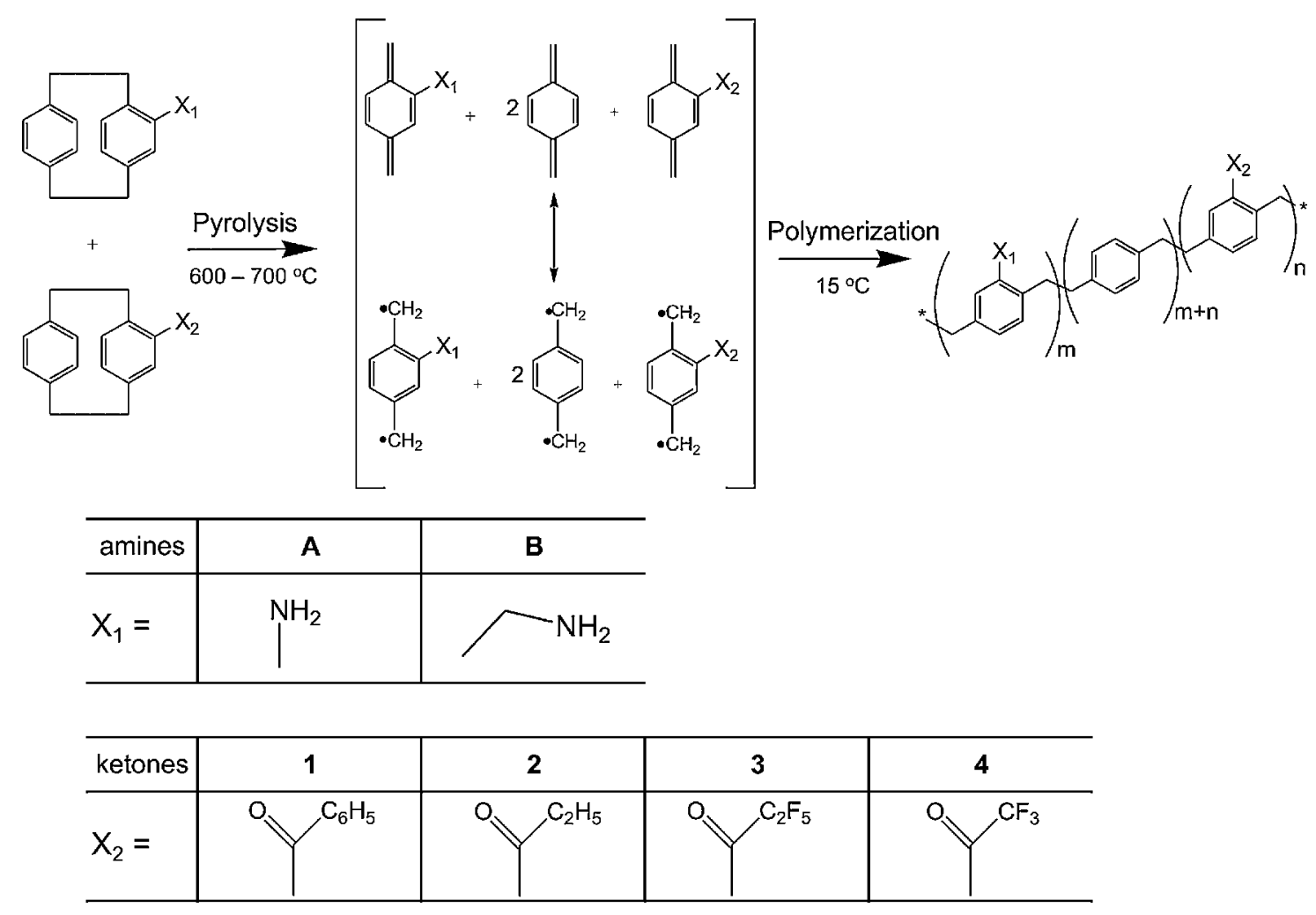

Scheme 3. Mechanism for CVD copolymerization of two different PCPs.

$\mathrm{CH}_{2} \mathrm{NH}_{2}$ ) required a pyrolysis temperature of $730^{\circ} \mathrm{C}$. All other copolymers were deposited using a pyrolysis temperature of $670^{\circ} \mathrm{C}$. Silicon, gold, stainless steel, or glass substrates were placed on a cooled sample holder $\left(15^{\circ} \mathrm{C}\right.$, unless stated otherwise) for polymer deposition. The sample holder was rotated to ensure more uniform film deposition. For copolymerization of varying molar feed ratios within one subgroup, all reaction conditions were maintained with the exception of the adjusted ratio of the two starting materials.

\section{Surface Characterization}

X-Ray photoelectron spectroscopy (XPS) data were recorded on an Axis Ultra X-ray photoelectron spectrometer (Kratos Analyticals, $\mathrm{UK}$ ) equipped with a monochromatized $\mathrm{Al} \mathrm{K}_{\alpha} \mathrm{X}$-ray source. All spectra were calibrated with respect to the non-functionalized aliphatic carbon with a binding energy of $285.0 \mathrm{eV}$. Coating thicknesses were recorded using an $\mathrm{EP}^{3}$-SW imaging ellipsometer (Nanofilm Technologie GmbH, Germany) at a wavelength of 532 $\mathrm{nm}$. Both nulling (four zones) and mapping experiments were performed at an angle of incidence of $60^{\circ}$, and an anisotropic Cauchy model was used to model the ellipsometric parameters psi and delta. FT-IR spectroscopy was performed on a Nicolet 6700 spectrometer utilizing the grazing angle accessory (Smart SAGA, Thermo) at a grazing angle of $85^{\circ}$.

\section{X-Ray Diffraction (XRD)}

To assess the crystallinity of functionalized PPX films, silicon substrates coated with the polymer of interest were examined by wide-angle XRD, using a Rigaku $12 \mathrm{~kW}$ high intensity rotary anode generator. All CVD films were examined both as deposited and after annealing. Prior to analysis, the polymer films were annealed for $14 \mathrm{~h}$ in an oven at a temperature of $120^{\circ} \mathrm{C}$.

\section{Enzyme-Linked Immunosorbent Assay (ELISA)}

Nunc 96-well plates and CVD-coated stainless steel disks placed in 24-well plates were coated with varying concentrations of human fibrinogen (Calbiochem) diluted in Dulbecco's phosphate buffered saline (PBS) overnight at $4{ }^{\circ} \mathrm{C}$. Surfaces were blocked ( $1 \%$ bovine serum albumin (BSA) in Dulbecco's PBS, $25^{\circ} \mathrm{C}, 1 \mathrm{~h}$ ), incubated with primary antibody (rabbit anti-human fibrinogen, Calbiochem, San Diego, CA; $1: 8000)$ in wash buffer $(0.5 \%$ Tween20 in Dulbecco's PBS) for $1 \mathrm{~h}$ at $25^{\circ} \mathrm{C}$, washed, and incubated with secondary antibody (goat anti-rabbit IgG H\&L chain, peroxidase conjugate, Calbiochem, 1:10000) in wash buffer for $1 \mathrm{~h}$ at $25^{\circ} \mathrm{C}$. Upon washing, the surfaces were incubated with 2,2'-azino-bis-(3-ethylbenzthiazoline-6-sulfonic acid) (ABTS) for $20 \mathrm{~min}$ at $25^{\circ} \mathrm{C}$. The enzymatic reaction was terminated with an $0.5 \mathrm{M} \mathrm{H}_{2} \mathrm{SO}_{4}$ stop solution and analyzed by absorbance measurement at $405 \mathrm{~nm}$.

\section{Growth of HUVECs and NIH3T3s on CVD-Coated Surfaces}

Human umbilical vein endothelial cells (HUVECs) (Cambrex, Walkersville, MD) or murine fibroblasts (NIH 3T3s) (ATCC, Manassas, VA) were cultured in tissue culture-treated polystyrene 
(TCPS) flasks (Corning, Lowell, MA), maintained at $37^{\circ} \mathrm{C}$ in a humidified atmosphere of $5 \% \mathrm{CO}_{2}$, and the media was replaced every other day until about $80 \%$ confluency was reached.

Functionalized PPX polymers and copolymers were deposited on $18 \mathrm{~mm}$, No. 1 glass cover slips. Polymer-coated cover slips were placed in sterile 12-well plates and incubated in Endothelial Growth Medium (Cambrex) prior to addition of cells. HUVECs were suspended at a density of $1 \times 10^{5}$ cells per $\mathrm{mL}$, and added at $1 \mathrm{~mL}$ per well. Phase contrast micrographs were taken 2 and $24 \mathrm{~h}$ post-seeding. At $24 \mathrm{~h}$ post-seeding, substrates with adherent cells were processed for immunocytochemistry. Samples were fixed and permeabilized (4\% paraformaldehyde, 0.5\% TritonX-100 in Dulbecco's PBS) for $15 \mathrm{~min}$, blocked (1\% BSA) for $30 \mathrm{~min}$, and stained with a primary antibody (anti-vinculin, Sigma, $1: 400$ ). Upon washing, cells were blocked ( $5 \%$ normal goat serum (Zymed, Carlsbad, CA)) and then stained with secondary antibody (Alexa Fluor 488-conjugated goat anti-mouse IgG1 (Invitrogen, Carlsbad, CA)), followed by rhodamine-conjugated phalloidin (Invitrogen). Finally, samples were mounted with Prolong Gold with DAPI (Invitrogen) for analysis by confocal microscopy.

NIH3T3s were grown on CVD-coated stainless steel disks or PVC films at a density of $7.5 \times 10^{4}$ cells per $\mathrm{mL}$ in 24 -well plates. All substrates were UV-sterilized for 30 min prior to addition of cells. After $24 \mathrm{~h}$ culture, cell samples were fixed, permeabilized, and then stained with rhodamine-conjugated phalloidin and Hoechst 33342 (Invitrogen). Substrates were mounted on cover slips with Prolong Gold, and imaged by confocal microscopy. All fluorescently labeled cells were visualized using a Zeiss LSM 510 confocal microscope at the Microscopy \& Image Analysis Laboratory of the University of Michigan.

\section{Glucose 6-Phosphatase Dehydrogenase (G6PD) Release}

Upon culturing NIH3T3 cells on bare or CVD-coated stainless steel disks for $24 \mathrm{~h}$, the cell culture media was collected and cleared by centrifugation at $1200 \mathrm{rpm}$ for $5 \mathrm{~min}$. Growth media alone or media from cells grown on TCPS, or that from lysed cells $(0.1 \%$ TritonX-100 for $5 \mathrm{~min}$ ) were used as controls. Cleared media were analyzed for G6PD content by Vybrant Cytotoxicity Assay Kit (Molecular Probes) following the manufacturer's directions. Fluorescence values (ex/em: 544/590 nm) were recorded every 5 min after addition of $2 \times$ resazurin reaction mixture to the well at $37^{\circ} \mathrm{C}$. For statistical analysis, results from all surfaces were compared to those of live cells grown on TCPS.

\section{Statistical Analysis}

Statistical analysis was performed using a general linear model ANOVA with Minitab software (Version 13.20, Minitab, State College, PA, USA). Unless otherwise indicated, $p$-values smaller than 0.05 were considered significant. Experiments were repeated as indicated.

\section{NMR Studies}

Carbonyl-functionalized $p$-xylenes were synthesized following an approach slightly modified from the synthetic procedures described for the corresponding PCPs. Model reactions of the carbonyl groups with hexanoic hydrazide were performed in an NMR tube and a sequence of ${ }^{1} \mathrm{H}$ NMR (Varian Inova, $400 \mathrm{MHz}$ ) spectra was collected in real-time. Prior to starting the reaction, a base ${ }^{1} \mathrm{H}$ NMR spectrum was taken as a reference. A slight excess of hexanoic hydrazide (1.1 equivalents) was dissolved in deuterated ethyl alcohol, and the functionalized $p$-xylene was added. Next, acetic acid was added to initiate the reaction, and data acquisition was started immediately after the sample was placed in the NMR spectrometer. NMR spectra were acquired every $7 \mathrm{~min}$ for two hours, and a final measurement was taken after $12 \mathrm{~h}$.

\section{r-Hirudin Immobilization and Binding Assay}

CVD-coated surfaces were incubated with hexamethylene diisocyanate (HDI) (1:10, w/w in absolute diethyl ether) for $24 \mathrm{~h}$ in argon atmosphere. The surfaces were then washed by Soxhlet extraction in absolute diethyl ether for $6 \mathrm{~h}$ and dried under vacuum. Hirudin was immobilized by incubating the surfaces with an $N$-terminal protected hirudin ( $500 \mathrm{nmol} \mathrm{ml}^{-1}$ in water) at $4{ }^{\circ} \mathrm{C}$ for $24 \mathrm{~h} .{ }^{[29]}$ The surfaces were washed extensively using wash buffer (PBS containing 0.1\% Tween-20). The protecting group was cleaved by exposing the surface to piperidine solution (10\% in deionized (DI) water) at $0{ }^{\circ} \mathrm{C}$ for $3 \mathrm{~h}$, and substrates were washed rigorously.

Hirudin binding was measured by an amidolytic assay (chromogenic assay) for thrombin. The surfaces were incubated with thrombin solution (20 U $\cdot \mathrm{mL}^{-1}$ in PBS, $\mathrm{pH}$ 7.4, Sigma-Aldrich, $\mathrm{MO}$ ) for $30 \mathrm{~min}$ at $25^{\circ} \mathrm{C}$, to which thrombin-active chromogenic substrate $\left(\mathrm{S}-2238,1 \mathrm{mmol} \cdot \mathrm{L}^{-1}\right.$ in DI water; DiaPharma Group Inc., $\mathrm{OH}$ ) was added. The reaction was stopped after $120 \mathrm{~s}$ with acetic acid (20\%), and the resulting colored solution was transferred to cuvettes for UV absorption reading at $405 \mathrm{~nm}$.

\section{Heparin Immobilization and Binding Assay}

CVD-coated substrates were incubated with a $500 \times 10^{-3} \mathrm{M}$ solution of adipic acid dihydrazide (Sigma-Aldrich, MO) in PBS for $24 \mathrm{~h}$. The substrates were then washed with wash buffer (PBS with $0.1 \%$ Tween 20 ). These hydrazide-functionalized substrates were immersed in heparin solution $\left(1 \mathrm{mg} \cdot \mathrm{mL}^{-1}\right.$ in water, Sigma-Aldrich, MO) overnight at $50^{\circ} \mathrm{C}$, washed with the wash buffer, and finally rinsed with water. To quantify the heparin immobilization, $1 \mathrm{~mL}$ of Toluidine blue $(0.0005 \%$, Sigma-Aldrich, MO) was placed with the heparin-modified surface and shaken vigorously, to which $1 \mathrm{~mL}$ of hexane was added. After the organic layer (which contained the heparin-Toluidine blue complex) was removed, the absorbance of the aqueous layer was measured by UV spectrophotometry at $631 \mathrm{~nm}$.

\section{Results and Discussion}

\section{Mono-Functionalized CVD Coatings}

CVD-based PPXs offer a high degree of flexibility for the types of functional groups that can be introduced and, 
therefore, provide a very versatile chemical modification platform. Such a strategy, however, requires synthesis of the appropriate PCPs and subsequent vapor deposition of well-defined reactive coatings, while maintaining the integrity of the functional groups under the conditions of CVD polymerization. Among the many reactive coatings that have been synthesized, ${ }^{[30]}$ carbonyl-functionalized polymers are of particular interest because of their favorable deposition properties and their selectivity towards hydrazide-functionalized ligands. ${ }^{[23]}$ When conducting CVD polymerization of functionalized PCPs $\left(-\mathrm{COC}_{6} \mathrm{H}_{5},-\mathrm{COC}_{2} \mathrm{H}_{5},-\mathrm{COC}_{2} \mathrm{~F}_{5},-\mathrm{COCF}_{3}\right)$, transparent polymer films with excellent adhesion were obtained for silicon, gold, stainless steel, and glass substrates. While the substrates used in this study were flat, we have recently demonstrated that the CVD process is also amenable to the coating of microspheres. ${ }^{[31]}$ In addition, a range of complex patterns can be created using masking techniques during CVD polymerization. ${ }^{[32]}$ FT-IR spectra of the polymers are shown in Figure 1 and correspond well with the expected polymer structures. ${ }^{[22,33]}$ Strong carbonyl stretches were present in the range of 1720 $1660 \mathrm{~cm}^{-1}$ in all spectra. Characteristic $\mathrm{C}-\mathrm{H}$ stretches, which are due to aromatic hydrogen atoms, were present between $3050-2910 \mathrm{~cm}^{-1}$. In addition, the spectrum of PPX- $\mathrm{COC}_{2} \mathrm{H}_{5}$ revealed a higher intensity band at $2930 \mathrm{~cm}^{-1}$, indicative of aliphatic hydrogen atoms. Strong FT-IR bands between 1204 and $1170 \mathrm{~cm}^{-1}$ are due to the fluorinated alkyl groups present in polymers PPX-COC $\mathrm{F}_{5}$ and PPX-COCF 3 . Collectively, the FT-IR spectra shown in Figure 1 confirm the expected structures of the carbonylfunctionalized polymers.

It has previously been observed that PPX derivatives with different functional groups can either be semicrystalline or amorphous. ${ }^{[21,26]}$ In fact, even subtle differences in the side group structure can influence the crystallinity of the polymer films. Therefore, XRD was used to assess the differences amongst the four different carbonyl-functionalized polymers, and the results were compared to unfunctionalized PPX (parylene N). Upon deposition, XRD spectra of all polymers except for the unfunctionalized PPX were void of any detectable signals, which indicates that these polymers were amorphous (data not shown). After annealing at $120^{\circ} \mathrm{C}$ for $14 \mathrm{~h}$, however, the fluoroalkyl-containing polymers (PPX-COC ${ }_{2} \mathrm{~F}_{5}$ and $\mathrm{PPX}-\mathrm{COCF}_{3}$ ) underwent significant chain remodeling as indicated by the appearance of sharp signals at $10.7^{\circ}$ and $21.2^{\circ}$ $\left(\mathrm{PPX}-\mathrm{COCF}_{3}\right)$, as well as $18.4^{\circ}\left(\mathrm{PPX}-\mathrm{COC}_{2} \mathrm{~F}_{5}\right)$ (Figure 2). In fact, these polymers underwent a transition from an amorphous polymer to become semi-crystalline. In contrast, $\mathrm{COC}_{6} \mathrm{H}_{5}$ and $\mathrm{COC}_{2} \mathrm{H}_{5}$-functionalized PPX coatings remained amorphous (Figure 2), even after exposure to identical annealing conditions.

Next, short-term cell adhesion on these polymers was examined by culturing HUVECs. As these experiments were intended to serve as a baseline assessment of studies with the copolymers described later in this communication, we included four carbonyl-functionalized PPXs along with two amine-functionalized coatings (poly[(4-aminomethyl- $p$-xylylene)-co-( $p$-xylylene)] and poly[(4-amino- $p$ xylylene)-co-( $p$-xylylene)]). In addition, a poly(t-lysine) (PLL)-coated surface and cytotoxic poly(vinyl chloride) (PVC) were used as positive and negative controls, respectively. As shown in Figure 3a, HUVECs grown on PLL are spread out and present an extensive actin cytoskeletal network, which is suggestive of growth-conducive interactions with the substrate. Interestingly, HUVECs cultured on the two amino-functionalized PPXs (Figure $3 b$ and c) showed a cell morphology similar to those cultured on the PLL-coated glass substrate. In contrast, HUVECs grown on carbonyl-functionalized PPXs presented different morphologies, as shown in Figure 3d-g; these cells appeared smaller and were less spread out, to various extents, as compared to those grown on PLL-coated cover slips or on amino-functionalized PPX. In addition, fewer cells adhered to these surfaces as observed by phase contrast micrographs of cells in culture up to $24 \mathrm{~h}$ (data not shown). These findings suggest that the carbonyl-

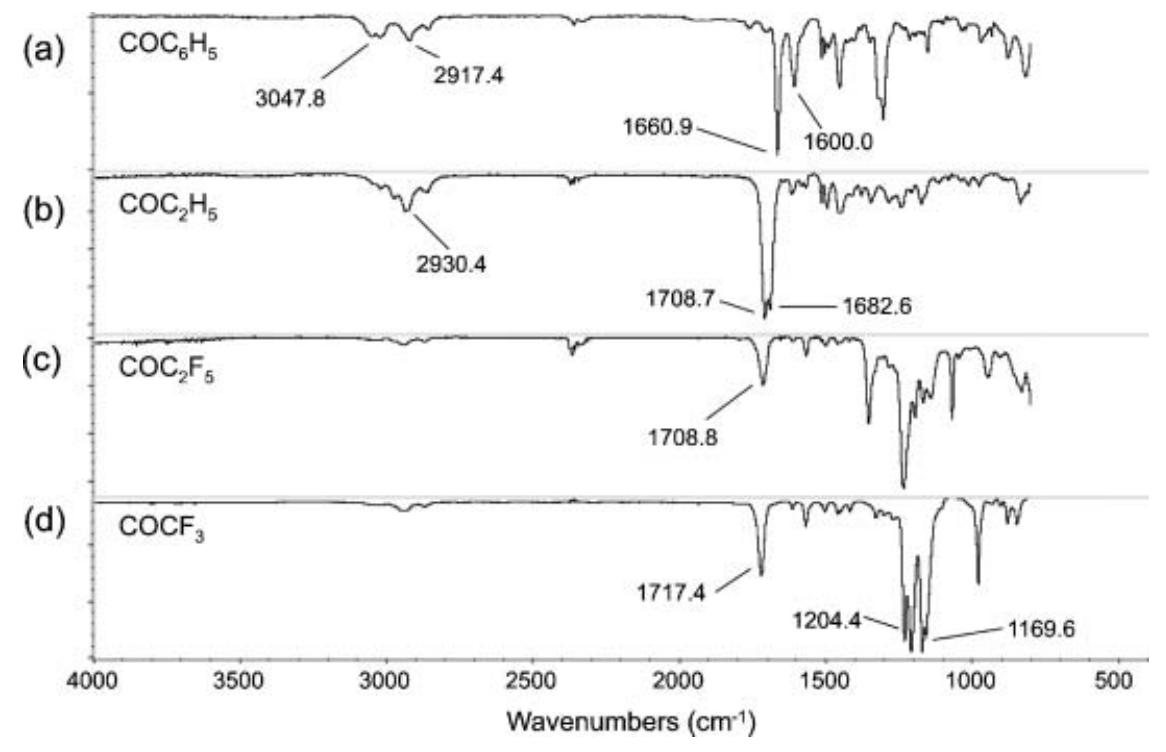

Figure 1. FT-IR spectra of PPX polymers containing the following functional modifications: a) $\mathrm{COC}_{6} \mathrm{H}_{5}$, b) $\mathrm{COC}_{2} \mathrm{H}_{5}$, c) $\mathrm{COC}_{2} \mathrm{~F}_{5}$, and d) $\mathrm{COCF}_{3}$. 


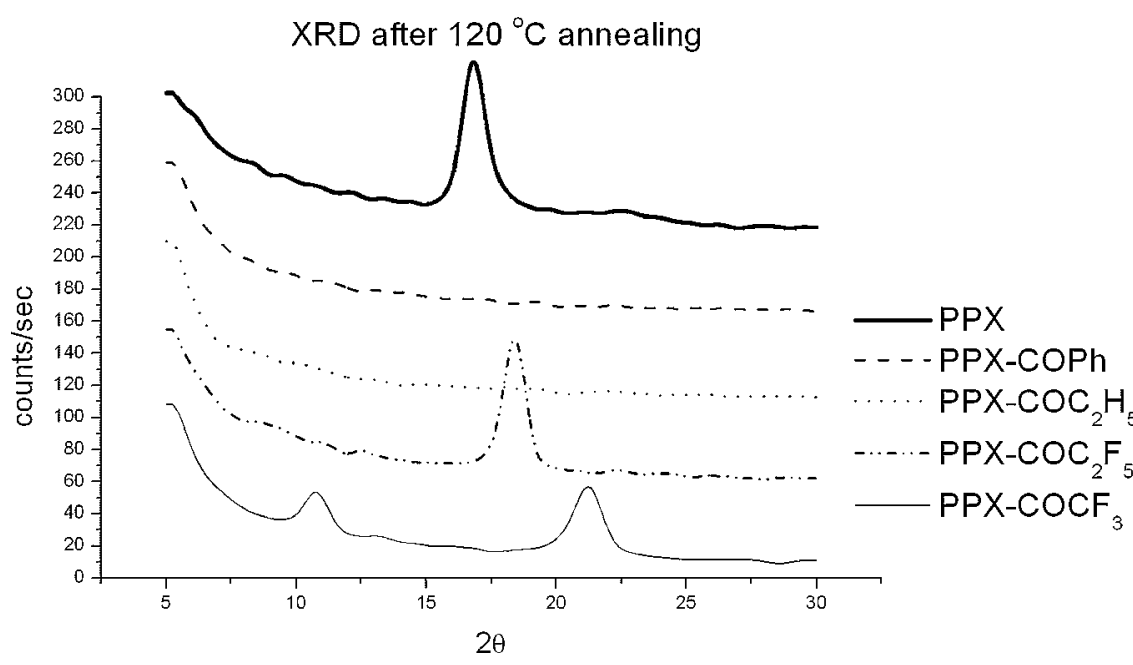

Figure 2. XRD of carbonyl-functionalized polymers upon annealing at $120^{\circ} \mathrm{C}$ for $14 \mathrm{~h}$.

spread out morphology of cells on PLL and amino-functionalized PPX surfaces in that cell adhesion on these substrates is likely stronger than that of cells on carbonyl-functionalized PPX. Together, results from this preliminary study suggest that differences in the functional side groups of the carbonyl-functionalized PPXs can result in polymer coatings with a wide range of different biological responses.

\section{Multi-Functionalized CVD Coatings}

The studies described thus far have evaluated surfaces coated with a

functionalized PPX may be less conducive to cell adhesion as compared to amino-functionalized PPX, as HUVECs minimize their contact with these polymer surfaces. In addition, the presence of vinculin was evaluated for these cells by immunocytochemistry. Vinculin is a membrane/ cytoskeletal protein, and a component of the focal adhesion protein complex, which binds the actin cytoskeleton to link cells to its substrate via adhesion molecules. ${ }^{[34]}$ Immunostaining revealed increased numbers of punctuate vinculin staining on cells cultured on PLL- and amino-functionalized PPX-coated surfaces relative to those cultured on carbonyl- functionalized PPX coatings (data not shown). These results corroborate the findings of the more single type of PPX. In the next set of experiments, multifunctional coatings which simultaneously present multiple chemical functional groups on the surfaces, were prepared by copolymerizing an amino-functionalized PCP $\left(-\mathrm{NH}_{2}\right.$ or $\left.-\mathrm{CH}_{2} \mathrm{NH}_{2}\right)$ with a carbonyl-functionalized PCP ($\mathrm{COC}_{6} \mathrm{H}_{5},-\mathrm{COC}_{2} \mathrm{H}_{5},-\mathrm{COC}_{2} \mathrm{~F}_{5}$, or $-\mathrm{COCF}_{3}$ ), as outlined in Scheme 3. In these experiments, the relative ratio of amino versus carbonyl groups was varied by altering the ratio of starting amounts of different PCPs used for CVD polymerization. For a given copolymer combination, all other process parameters, including the total amount of starting materials, pressure, and sublimation, pyrolysis, and deposition temperatures were kept constant.

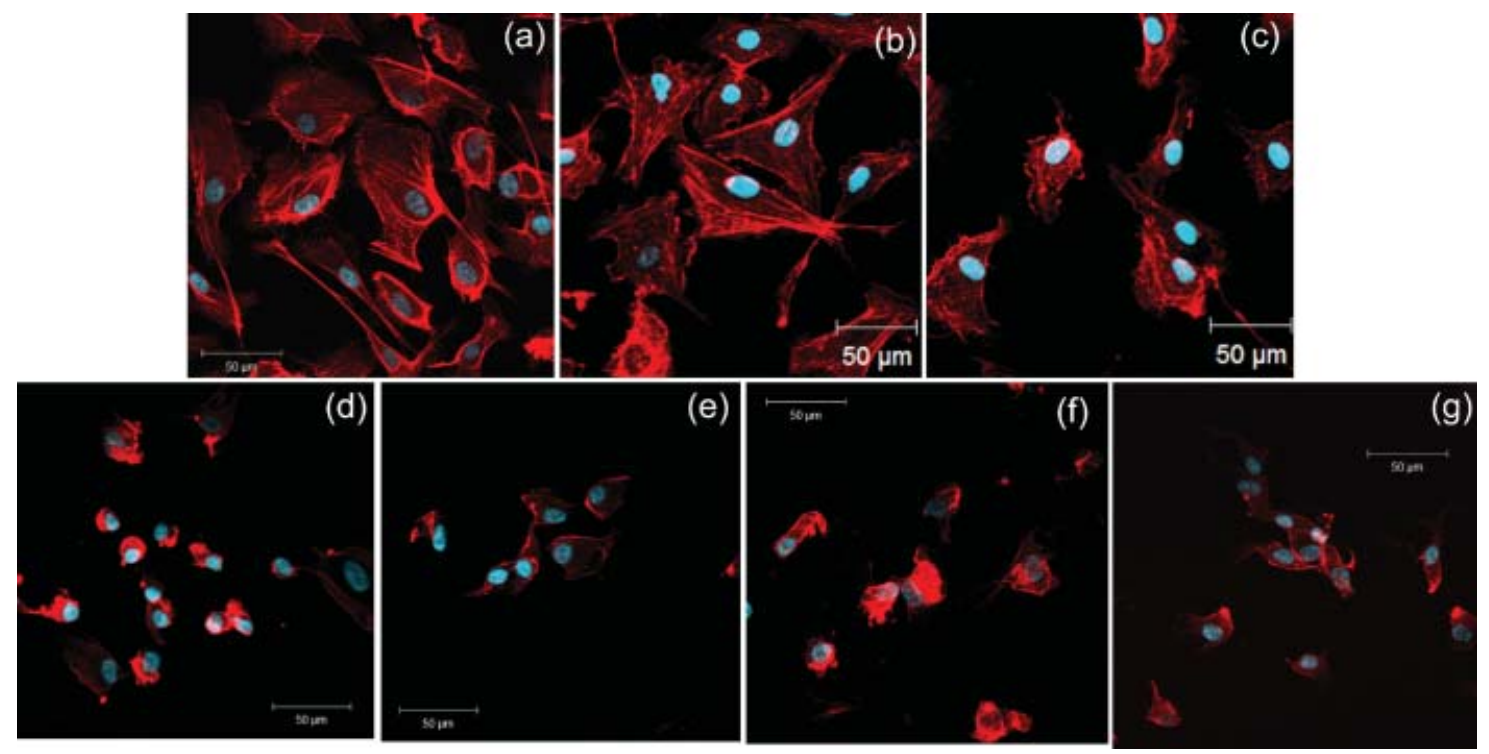

Figure 3. Confocal microscopy images of HUVECs grown on a) a poly(L-lysine)-coated cover slip, b) $\left.\left.\mathrm{PPX}_{-} \mathrm{CH}_{2} \mathrm{NH}_{2}, \mathrm{c}\right) \mathrm{PPX}-\mathrm{NH}_{2}, \mathrm{~d}\right) \mathrm{PPX}-\mathrm{COC}_{6} \mathrm{H}_{5}$, e) $P P X-\mathrm{COC}_{2} \mathrm{H}_{5}$, f) PPX-COC $\mathrm{F}_{5}$, and g) PPX-COCF 3 surfaces. Red: actin cytoskeleton (rhodamine-phalloidin), blue: nucleus (DAPI). $n=3$, representative images shown. All scale bars are $50 \mu \mathrm{m}$. 
By adjusting the ratio of monomers loaded into the CVD sublimation zone, different molar ratios were prepared for each polymer combination, which resulted in a variety of copolymers. For this approach to be successful, special care was taken to ensure that the deposition rates of both PCPs were similar. To illustrate generalized trends, selected FT-IR spectra are shown in Figure 4 and 5. shows FT-IR spectra for copolymer PPX- $\mathrm{NH}_{2} /-\mathrm{COC}_{2} \mathrm{~F}_{5}$ deposited in five different ratios as well as spectra of the mono-functional polymers PPX-NH $\mathrm{N}_{2}$ and PPX- $\mathrm{COC}_{2} \mathrm{~F}_{5}$ as references. FT-IR bands characteristic of a N-H bond occur at 3461.5 and $3380.7 \mathrm{~cm}^{-1}$, whereas stretches characteristic of $\mathrm{COC}_{2} \mathrm{~F}_{5}$ occur at $1711.2(C=0), 1351.3$, and $1231.0 \mathrm{~cm}^{-1}(C-F)$. Even for ratios with low carbonyl content, the $\mathrm{C}-\mathrm{F}$ stretches were clearly distinguished. As the amount of PPX- $\mathrm{COC}_{2} \mathrm{~F}_{5}$ was increased, ratios of peaks characteristic to $\mathrm{NH}_{2}$ stretches and $\mathrm{COC}_{2} \mathrm{~F}_{5}$ changed accordingly. A characteristic band at $1625.9 \mathrm{~cm}^{-1}$ was detected in all amino-containing polymers. Likewise, $\mathrm{PPX}-\mathrm{CH}_{2} \mathrm{NH}_{2} /-\mathrm{COC}_{2} \mathrm{H}_{5}$ copolymers showed similar trends in the FT-IR spectra as the ratio of the amount of starting material was varied systematically (Figure 5). For example, bands at 3361.6 and $1641.5 \mathrm{~cm}^{-1}$ were distinct until a ratio of 1:2 was reached. A vibration at $1641.5 \mathrm{~cm}^{-1}$ is characteristic of $\mathrm{NH}_{2}$ scissoring stretches, while a vibration at $3361.6 \mathrm{~cm}^{-1}$ indicates $\mathrm{N}-\mathrm{H}$ stretches. As the concentration of PPX- $\mathrm{COC}_{2} \mathrm{H}_{5}$ increased, these vibrations gradually disappeared. Other subtle changes in the FT-IR spectra include a change in $\mathrm{C}-\mathrm{H}$ bands with respect to their relative intensities. With increasing content of PPX- $\mathrm{CH}_{2} \mathrm{NH}_{2}$ in the copolymer, an increase in the aliphatic $\mathrm{C}^{-}$ $\mathrm{H}$ bands attributed to the $\mathrm{COC}_{2} \mathrm{H}_{5}$ group was observed. There appears to be no evidence of a cross-reaction between the amine and carbonyl functional groups, as indicated by an imine stretch $\left(1655 \mathrm{~cm}^{-1}\right)$ (Figure 4 and 5). In addition, for each copolymer spectrum, all FT-IR bands can be accounted for based on the spectra of the constituting mono-functional polymers (Figure 1). Furthermore, the copolymer composition can be correlated to the monomer sublimation rates, which were controlled by the sublimation temperatures. Compositions were determined using XPS, and the sublimation temperatures of both monomers were recorded in situ using a thermocouple. Table 1 details the results of this study.

In many cases, homogeneous deposition of coatings is an impor- tant technological requirement. The deposition chamber used in this study is large enough for temperature gradients within the chamber and/or on the sample holder to form. Such differences, if they exist, may impede accurate deposition of defined copolymer ratios. To assess the potential inhomogeneities created during CVD copolymerization as a result of temperature differences, copolymer PPX- $\mathrm{CH}_{2} \mathrm{NH}_{2} /-\mathrm{COCF}_{3}$ (1:1 monomer ratio) was deposited onto nine different samples, each located at various positions within the sample holder (Figure 6). The experimental conditions were maintained as described for other CVD copolymerization procedures, with the exception that the sample holder was not rotated and the substrate temperature was systematically varied. FT-IR spectroscopy was used to obtain the ratio of $\mathrm{C}-\mathrm{N}$ to $\mathrm{C}=\mathrm{O}$ bands, which served as an indicator of the copolymer ratios. For each temperature, sample \#2 (Figure 6) was used as a reference; all sample peak ratios were normalized by the peak ratio of sample \#2. As shown in Figure 6b, the average ratio of two functional groups remained relatively constant across all deposition temperatures, which suggests no significant compositional differences on the sample holder, even at different substrate temperatures.

Although FT-IR spectra indicated agreement of the bulk copolymer composition with the loaded monomer

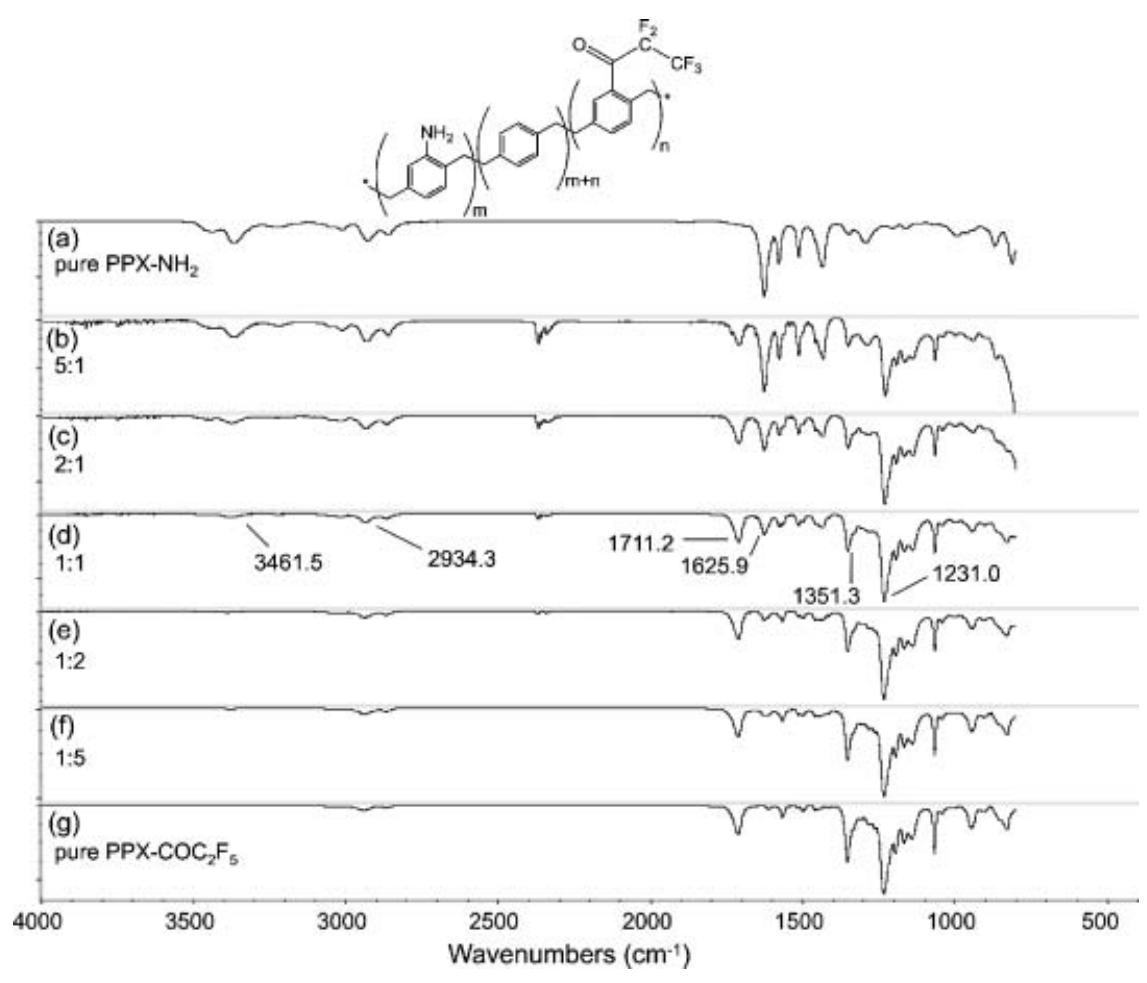

Figure 4. FT-IR spectra of CVD copolymer $\left(-\mathrm{NH}_{2} /-\mathrm{COC}_{2} \mathrm{~F}_{5}\right)$, copolymerized in different molar ratios of PPX-NH $\mathrm{NH}_{2}$ to PPX-COC $\mathrm{F}_{5}$. a) Pure PPX- $\mathrm{NH}_{2}$, b) 5:1, c) 2:1, d) 1:1, e) 1:2, f) 1:5, g) pure $\mathrm{PPX}-\mathrm{COC}_{2} \mathrm{~F}_{5}$. 


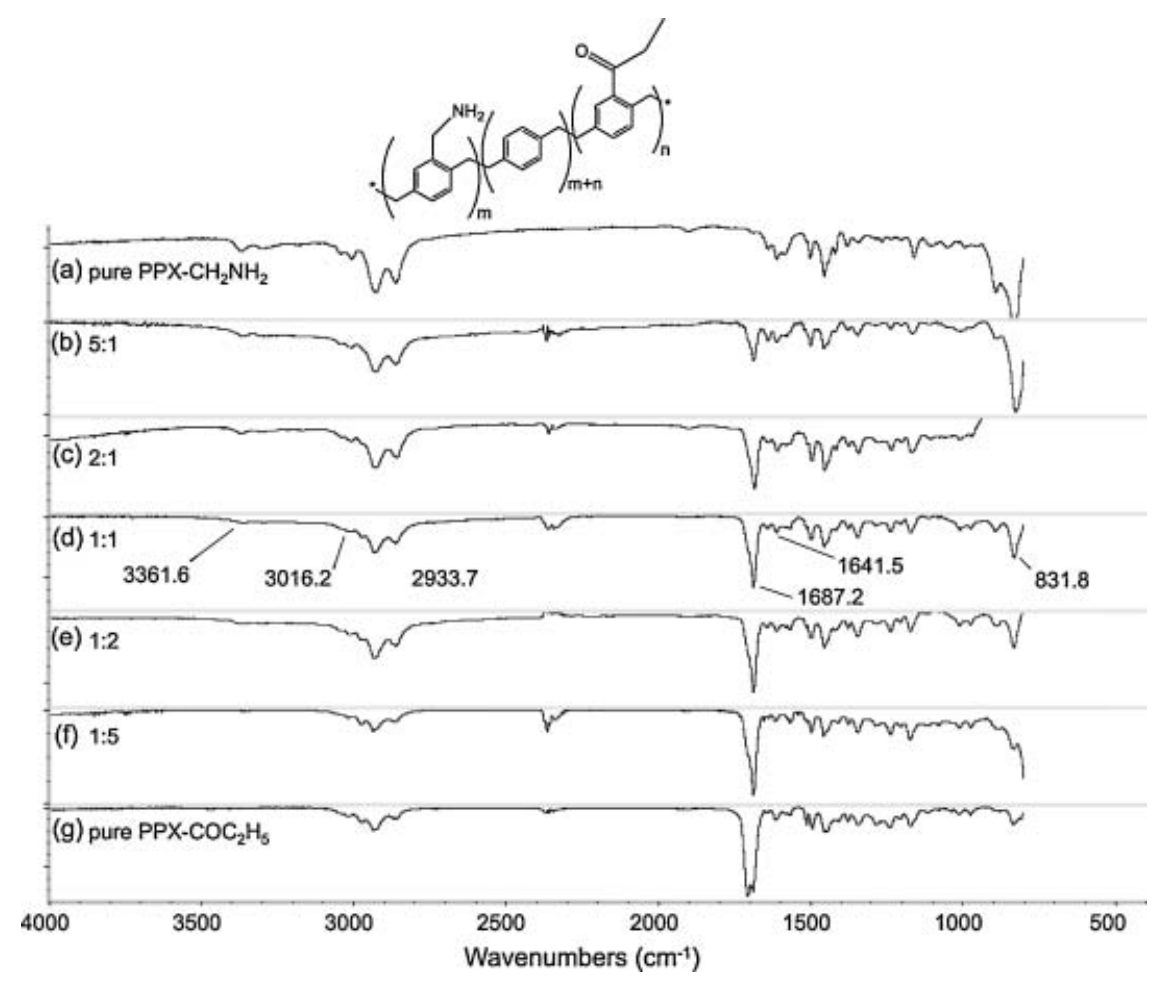

Figure 5. FT-IR spectra of CVD copolymer $\left(-\mathrm{CH}_{2} \mathrm{NH}_{2} /-\mathrm{COC}_{2} \mathrm{H}_{5}\right)$ copolymerized to different molar ratios of PPX- $\mathrm{CH}_{2} \mathrm{NH}_{2}$ and PPX-COC $\mathrm{F}_{5}$. a) Pure PPX- $\mathrm{CH}_{2} \mathrm{NH}_{2}$, b) 5:1, c) 2:1, d) 1:1, e) 1:2, f) 1:5, and g) pure PPX- $-\mathrm{COC}_{2} \mathrm{H}_{5}$.

ratio, this method has limited surface sensitivity and provides averaged information of the entire polymer films. To assess the actual surface composition of the copolymer films, surfaces were analyzed by XPS, which can detect the atomistic composition of a surface, usually within 5-10 $\mathrm{nm}$. This technique can provide a survey spectrum of all

Table 1. XPS composition of copolymer (PPX- $\left.\mathrm{CH}_{2} \mathrm{NH}_{2} /-\mathrm{COCF}_{3}\right)$, deposited using various monomer sublimation temperatures. A monomer loading ratio of 1:1 was used for all depositions.

\begin{tabular}{|c|c|c|c|}
\hline \multirow[t]{2}{*}{$\begin{array}{l}\text { Mole } \\
\text { fraction } \\
\mathrm{CH}_{2} \mathrm{NH}_{2}\end{array}$} & $T\left(-\mathrm{CH}_{2} \mathrm{NH}_{2}\right)$ & $T\left(-\mathrm{COCF}_{3}\right)$ & $\begin{array}{c}\text { Total } \\
\text { growth } \\
\text { rate }\end{array}$ \\
\hline & ${ }^{\circ} \mathrm{C}$ & ${ }^{\circ} \mathrm{C}$ & $\mathrm{As}^{-1}$ \\
\hline 0 & 88 & 95 & 0.7 \\
\hline 0.18 & 93.6 & 73.8 & 0.6 \\
\hline 0.26 & 95.8 & 64.8 & 0.6 \\
\hline 0.4 & 104.3 & 58.3 & 0.7 \\
\hline 0.49 & 110.6 & 51 & 0.7 \\
\hline 0.62 & 115.8 & 40.7 & 0.7 \\
\hline 0.73 & 137.6 & 40 & 0.7 \\
\hline 0.91 & 142 & 35 & 0.7 \\
\hline
\end{tabular}

atoms present, as well as a highresolution scan that provides information about the binding state of a particular element. Table 2 summarizes the chemical composition of all 1:1 ratios of the entire group of amino/carbonyl copolymers. Experimental data are compared to theoretical values obtained on the basis of the starting materials assuming a 1:1 ratio of the two PCPs. Generally, all copolymers demonstrated good agreement between experimental values and theoretical compositions. All high-resolution $C$ is spectra revealed $\pi-\pi^{*}$ transitions, which are characteristic of aromatic polymers. ${ }^{[35]}$ Nevertheless, discrepancies existed between experimental results and theoretically calculated values. Even though a 1:1 monomer loading ratio is used, fluctuations in ratios can occur during monomer sublimation. When discussing the results of the XPS study, we used the ratio of $\mathrm{N}$ and $\mathrm{F}$ molecules (N/F ratio) revealed by the XPS survey spectra to determine the copolymer ratio. As the observed trends were quite similar amongst the copolymers studied herein, we selected the copolymer PPX- $\mathrm{CH}_{2} \mathrm{NH}_{2} /-\mathrm{COCF}_{3}$ as an example in the following discussion. Figure 7 shows a tight correspondence between the loaded monomer ratio and the actual composition of the copolymer as indicated by the N/F ratio measured by XPS.

\section{Biocompatibility Studies}

In order for such a polymer to function as an advanced biointerface, its compatibility with cells must be assessed. We have demonstrated the ability of copolymer PPX- $\mathrm{CH}_{2} \mathrm{NH}_{2} /-\mathrm{COCF}_{3}$ to immobilize multiple ligands in defined ratios, ${ }^{[26]}$ but its biocompatibility has not yet been tested. As shown in Figure 3, general differences among the homopolymers existed with regard to HUVEC attachment and morphology. To study the biocompatibility of the copolymers, we investigated several cellular responses upon culture on CVD films. Initially, protein adsorption on these CVD polymer coatings was evaluated using fibrinogen as a model protein. Fibrinogen was chosen as a model protein because of its role in blood coagulation. ${ }^{[36]}$ As many biologically relevant devices contact blood upon implantation, fibrinogen adsorption behavior may be an important indicator for potential pro-thrombotic activity. As shown in 


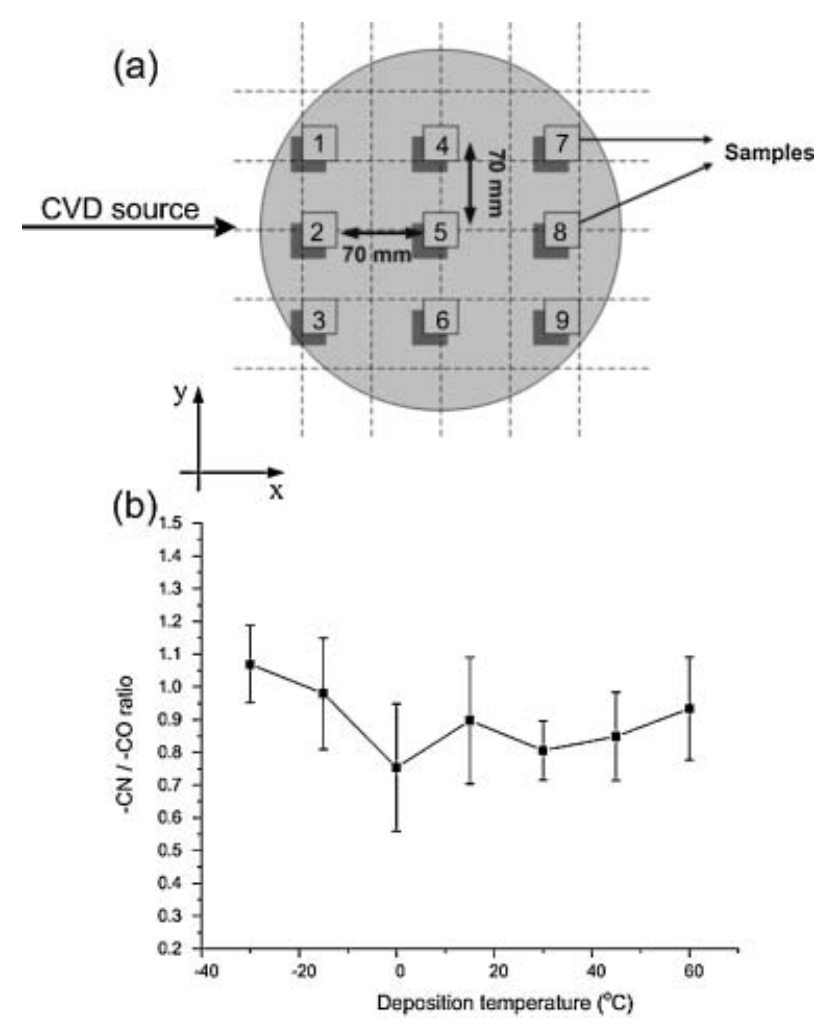

Figure 6. a) Schematic representation of substrate positions arranged on the CVD sample holder. b) Plot of FT-IR peak ratios $(\mathrm{C}-\mathrm{N}$ to $\mathrm{C}=\mathrm{O})$, with respect to substrate temperature.

Figure 8, adsorption of fibrinogen on the CVD surfaces evaluated (mono-functional polymers $\mathrm{PPX}-\mathrm{CH}_{2} \mathrm{NH}_{2}$ and $\mathrm{PPX}-\mathrm{COCF}_{3}$, and $\mathrm{PPX}-\mathrm{CH}_{2} \mathrm{NH}_{2} /-\mathrm{COCF}_{3}$ at a 1:1 ratio) was not significantly different from that of TCPS, but higher than on stainless steel.

As cell attachment onto CVD surfaces supports potential biomedical applications of the CVD polymer coatings, the biocompatibility of these coatings was assessed using NIH3T3 fibroblasts. These cells were cultured and grown on various CVD surfaces and their release of glucose-6phosphate dehydrogenase (G6PD) was measured. This enzyme is normally intracellular but upon a compromise in cell membrane integrity or lysis it is released into the surrounding media. ${ }^{[37]}$ Thus, the amount of G6PD detected in cell culture media may be indicative of surface cytotoxicity. As compared to a media of live cells, significantly higher amounts of G6PD were detected in a media of lysed cells and those grown on PVC (Figure 9). In contrast, lower G6PD release was observed from cells grown on PPX- $\mathrm{CH}_{2} \mathrm{NH}_{2}$, the 1:1 copolymer, and PPX-COCF as compared to live cells, which suggests that CVD surfaces may not cause cell death or lysis of cells cultured on TCPS at the time point evaluated.
Morphologies of NIH3T3 fibroblasts grown on CVD homopolymers and copolymer PPX- $\mathrm{CH}_{2} \mathrm{NH}_{2} /-\mathrm{COCF}_{3}$ were evaluated (Figure 10). As expected, murine fibroblasts showed reduced growth on PVC disks, as many of the initially seeded cells did not adhere or were detached during washing steps. Cells that remained adherent were small in size and round in shape, which suggests a lack of spreading and contact with the surface. NIH3T3s grown on PPX $-\mathrm{CH}_{2} \mathrm{NH}_{2}$ and PPX- $\mathrm{CH}_{2} \mathrm{NH}_{2} /-\mathrm{COCF}_{3}$ surfaces showed morphologies comparable to those grown on a PLL cover slip, with cell spreading as indicated by actin filaments. On PPX-COCF 3 , cells mostly aggregated, although more cells remained adherent on this surface and more spreading was observed than on PVC. In this set of experiments, the introduction of polymer $\mathrm{PPX}-\mathrm{CH}_{2} \mathrm{NH}_{2}$ to polymer PPX-COCF 3 , as copolymer PPX- $\mathrm{CH}_{2} \mathrm{NH}_{2} /-\mathrm{COCF}_{3}$, improved NIH3T3 adhesion to the polymer coating.

\section{Reactivity Study}

An ultimate goal of developing carbonyl-functionalized copolymers is to simultaneously immobilize multiple ligands. For the purpose of having orthogonal reactivity under physiological conditions, it is necessary to understand the relative chemical reactivity of the different carbonyl groups towards target molecules (hydrazides). In this context, we analyzed the reaction kinetics of these different carbonyl functionalities using in-situ ${ }^{1} \mathrm{H}$ NMR spectroscopy. Rather than reacting functionalized PCP monomers, we chose to synthesize correspondingly functionalized $p$-xylenes, because the constrained ring system of the PCPs significantly alters their chemical reactivity and disqualifies them as model reactants for PPXs. Functionalized $p$-xylenes may be considered as the smallest repetition unit of the polymer coatings and, therefore, more closely resembles the PPX chain.

By integrating two specific peaks on the NMR spectra, one characteristic of the reactants $(-\mathrm{CH})$ and the other one indicating the product $(-\mathrm{C}=\mathrm{N}-\mathrm{NH})$, the percentage yield of the product was evaluated. Measurement frequency was decreased when the percentage yield reached a plateau. The percentage yields were plotted as a function of time for the different reactions with functionalized $p$-xylene derivatives. Figure 11 shows kinetic curves fitted to the experimental data. For most $p$-xylenes, NMR peaks characteristic of the product were evident within 15-20 min of initiating the reaction. NMR spectra for benzoylfunctionalized $p$-xylene showed no signals that were characteristic of the product over reaction durations as long as $15 \mathrm{~h}$. The fluorinated keto group was more reactive than non-fluorinated groups. Of the functional groups, $\mathrm{COCF}_{3}$ was the most reactive, followed by $\mathrm{COC}_{2} \mathrm{~F}_{5}, \mathrm{COC}_{2} \mathrm{H}_{5}$, and $\mathrm{COC}_{6} \mathrm{H}_{5}$ in order of decreasing reactivity. The benzoyl $\left(\mathrm{COC}_{6} \mathrm{H}_{5}\right)$ group yielded essentially no product within the 
Table 2. Elemental compositions of CVD copolymers containing 1:1 ratios of PPX- $\mathrm{NH}_{2}$ to $P P X-R\left(\mathrm{NH}_{2}\right.$ series A) and 1:1 ratios of $\mathrm{PPX}-\mathrm{CH} \mathrm{NH}_{2}$ to PPX-R ( $\mathrm{NH}_{2}$ series $\left.\mathrm{B}\right)$ determined by XPS. Atomic composition results are shown on the top half of each series, while high resolution $\mathrm{C}_{15}$ spectra results are shown on the bottom. Theoretical calculations are based upon ideal deposition of the copolymer ratio.

\begin{tabular}{|c|c|c|c|c|c|c|c|c|}
\hline \multirow[t]{3}{*}{ Component } & \multicolumn{8}{|c|}{$\mathbf{R}$} \\
\hline & \multicolumn{2}{|c|}{$\mathrm{COC}_{6} \mathrm{H}_{5}(1)$} & \multicolumn{2}{|c|}{$\mathrm{COC}_{2} \mathrm{H}_{5}(2)$} & \multicolumn{2}{|c|}{$\mathrm{COC}_{2} \mathrm{~F}_{5}(3)$} & \multicolumn{2}{|c|}{$\mathrm{COCF}_{3}(4)$} \\
\hline & exper & theor & exper & theor & exper & theor & exper & theor \\
\hline $\mathrm{NH}_{2}$ series $(\mathrm{A})$ & & & & & & & & \\
\hline $\mathrm{F}$ & - & - & - & - & 15.35 & 14.37 & 11.8 & 9.44 \\
\hline $\mathrm{O}$ & 1.69 & 2.04 & 5.04 & 2.70 & 4.56 & 2.86 & 5.42 & 3.14 \\
\hline $\mathrm{N}$ & 2.01 & 2.04 & 2.66 & 2.70 & 2.61 & 2.86 & 3.71 & 3.14 \\
\hline C (total) & 96.3 & 95.92 & 92.30 & 94.60 & 77.48 & 79.91 & 79.06 & 84.28 \\
\hline$C-C$ & 84.01 & 87.76 & 76.26 & 83.78 & 60.53 & 68.39 & 66.02 & 74.86 \\
\hline $\mathrm{C}-\mathrm{N}$ & 2.33 & 2.04 & 2.33 & 2.70 & 2.54 & 2.88 & 2.17 & 3.14 \\
\hline$C-C=O$ & 3.8 & 4.08 & 4.58 & 5.41 & - & - & - & - \\
\hline$C=O$ & 1.91 & 2.04 & 4.37 & 2.70 & 3.39 & 2.88 & 4.25 & 3.14 \\
\hline$\pi \rightarrow \pi^{*}$ & 4.25 & - & 4.76 & - & 4.04 & - & 3.07 & - \\
\hline $\mathrm{CF}_{3}$ & - & - & - & - & 3.49 & 2.88 & 3.56 & 3.14 \\
\hline $\mathrm{CF}_{2}$ & - & - & - & - & 3.49 & 2.88 & - & - \\
\hline
\end{tabular}

\section{$\mathrm{CH}_{2} \mathrm{NH}_{2}$ series (B)}

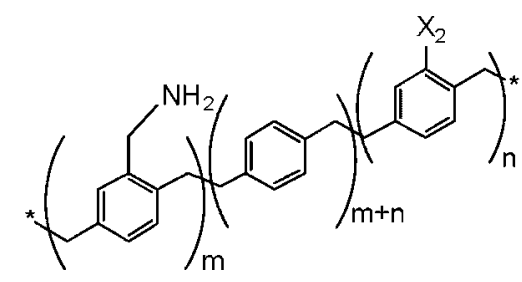

$\begin{array}{lcccccccc}\mathrm{F} & - & - & - & - & 17.18 & 13.97 & 8.54 & 9.14 \\ \mathrm{O} & 1.9 & 2.00 & 2.63 & 4.49 & 4.84 & 2.79 & 5.35 & 3.05 \\ \mathrm{~N} & 1.23 & 2.00 & 2.63 & 2.36 & 1.90 & 2.79 & 2.84 & 3.05 \\ \mathrm{C} \text { (total) } & 96.87 & 96.00 & 94.74 & 93.15 & 76.08 & 80.45 & 83.26 & 84.76 \\ \mathrm{C}-\mathrm{C} & 86.46 & 88.00 & 79.40 & 82.79 & 59.14 & 69.29 & 71.40 & 75.61 \\ \mathrm{C}-\mathrm{N} & 1.30 & 2.00 & 2.55 & 2.59 & 2.41 & 2.79 & 2.50 & 3.05 \\ \mathrm{C}-\mathrm{C}=\mathrm{O} & 3.65 & 4.00 & 5.36 & 5.18 & - & - & - & - \\ \mathrm{C}=\mathrm{O} & 1.88 & 2.00 & 3.77 & 2.59 & 3.67 & 2.79 & 2.67 & 3.05 \\ \pi \rightarrow \pi^{*} & 3.58 & - & 3.66 & - & 2.94 & - & 3.43 & - \\ \mathrm{CF}_{3} & - & - & - & - & 3.96 & 2.79 & 3.25 & 3.05 \\ \mathrm{CF}_{2} & - & - & - & - & 3.96 & 2.79 & - & -\end{array}$




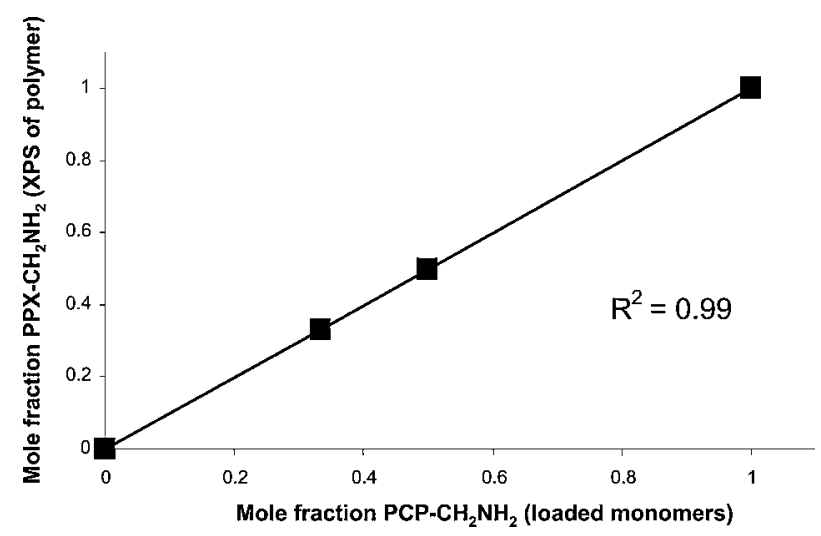

Figure 7. Graph of copolymer ratios of $\left(-\mathrm{CH}_{2} \mathrm{NH}_{2}\right.$ to $-\mathrm{COCF}_{3}$ plotted against their monomer loading ratios.

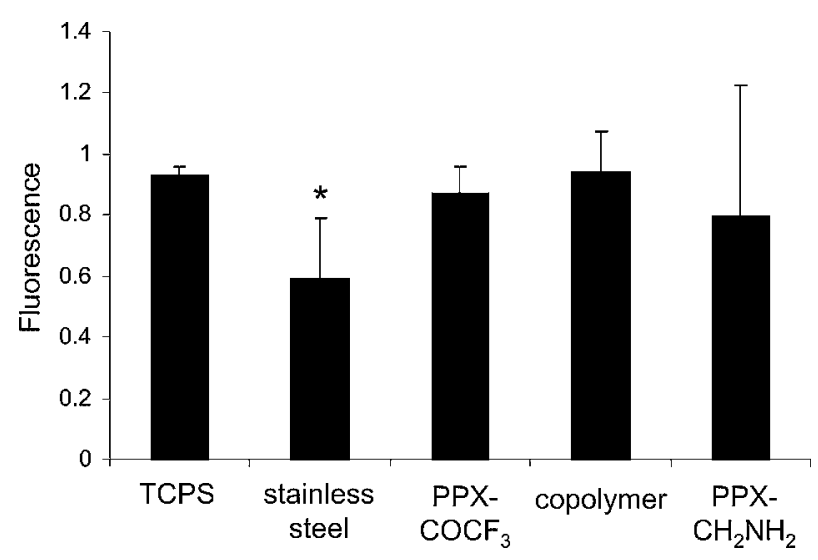

Figure 8. Fibrinogen adsorption on various substrates. Normalized fluorescence values are reported. Results were compared to TCPS. $n=3,{ }^{*}: p<0.05$.

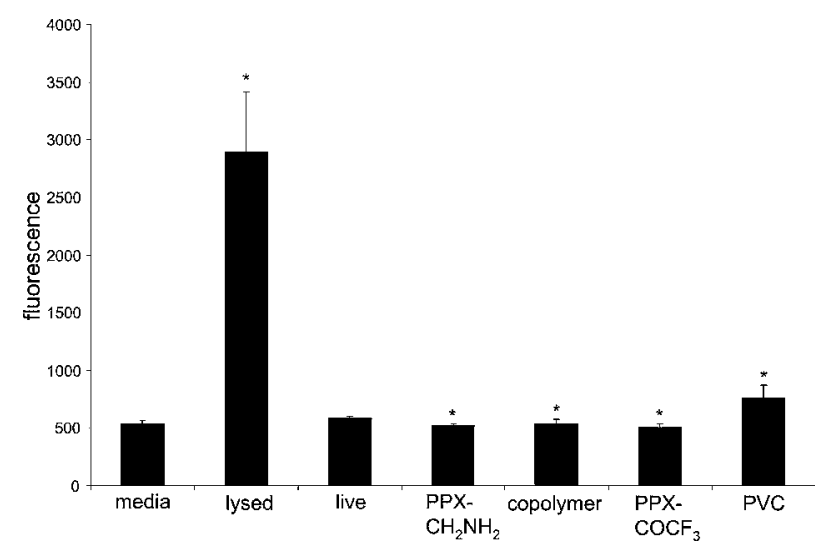

Figure 9. G6PD release from $\mathrm{NIH} 3^{T} 3$ s grown on various substrates. Fluorescence values are reported. Results are compared to G6PD measured in media supporting live cells. $n=3,{ }^{*}$ : $p<0.05$. evaluated reaction times. On the basis of these experiments, the trifluoroacetyl $\left(\mathrm{COCF}_{3}\right)$ group was selected for further multifunctional surface immobilization.

For surface immobilization, we used r-hirudin, a recombinant protein that deactivates thrombin. Thrombin plays a central role in blood coagulation and mediates restenosis. ${ }^{[38]}$ Thus, the immobilization of hirudin may be a possible remediation approach for blood-contacting devices, such as cardiovascular stents. In addition, heparin, a highly sulfated glycosaminoglycan anticoagulant, was utilized for immobilization. Hirudin and heparin are expected to be immobilized on the copolymer coating of $-\mathrm{CH}_{2} \mathrm{NH}_{2} /-\mathrm{COCF}_{3}$ through the aminomethyl groups by a diisocyanate linker ${ }^{[39]}$ and carbonyl groups by adipic acid dihydrazide, ${ }^{[23]}$ respectively.

For r-hirudin immobilization, the substrates were incubated with hexamethylene diisocyanate, which is reactive towards amine groups. ${ }^{[29]}$ FT-IR spectroscopy confirmed the presence of the isocyanate (NCO) group on the amine and the copolymer surfaces with a stretch at $2275 \mathrm{~cm}^{-1}$, which was absent in the FT IR spectra of the ketone surfaces. After immobilization, r-hirudin was deprotected to restore the biomolecular activity, and its binding capacity was measured via a chromogenic substrate (S-2238) for thrombin. ${ }^{[29]}$ In this assay, surfacebound hirudin complexes thrombin, whereas free thrombin cleaves the chromogenic substrate. As shown in Figure 12a, the absorbance was lower for the aminecontaining homopolymer PPX-CH $\mathrm{NH}_{2}$ and the copolymer PPX- $\mathrm{CH}_{2} \mathrm{NH}_{2} /-\mathrm{COCF}_{3}$, as compared to the control surface of stainless steel, which indicates a higher amount of surface-bound hirudin on the surfaces of PPX- $\mathrm{CH}_{2} \mathrm{NH}_{2}$ or PPX- $\mathrm{CH}_{2} \mathrm{NH}_{2} /-\mathrm{COCF}_{3}$. Immobilized heparin was photometrically quantified using a Toluidine blue test. ${ }^{[40]}$ As the activity of surface-bound heparin increases, more dye is surface-bound, leaving less dye in the solution, which yields a lower UV absorbance. Figure $12 \mathrm{~b}$ shows that the absorbance per $\mathrm{cm}^{2}$ was lowest for PPX-COCF 3 compared to the copolymer PPX- $\mathrm{CH}_{2} \mathrm{NH}_{2} /-\mathrm{COCF}_{3}$ and the stainless steel control, which indicates the higher amount of heparin bound to PPX- $\mathrm{COCF}_{3}$.

While these results demonstrate successful reactivity of the copolymer towards both molecules, precise control of the number of molecules immobilized to the surface poses a challenge. Theoretically, the copolymer contains half the number of active immobilization sites compared to the homopolymer. However, this preliminary study suggests that not all groups are used for r-hirudin immobilization. This may be due to steric hindrances, whereby immobilization of r-hirudin onto $\mathrm{CH}_{2} \mathrm{NH}_{2}$ groups results in masking of other $\mathrm{CH}_{2} \mathrm{NH}_{2}$ sites available for immobilization. As such, an appropriate choice of spacers for the successful control of the ratio of immobilized agents will be among future challenges. 

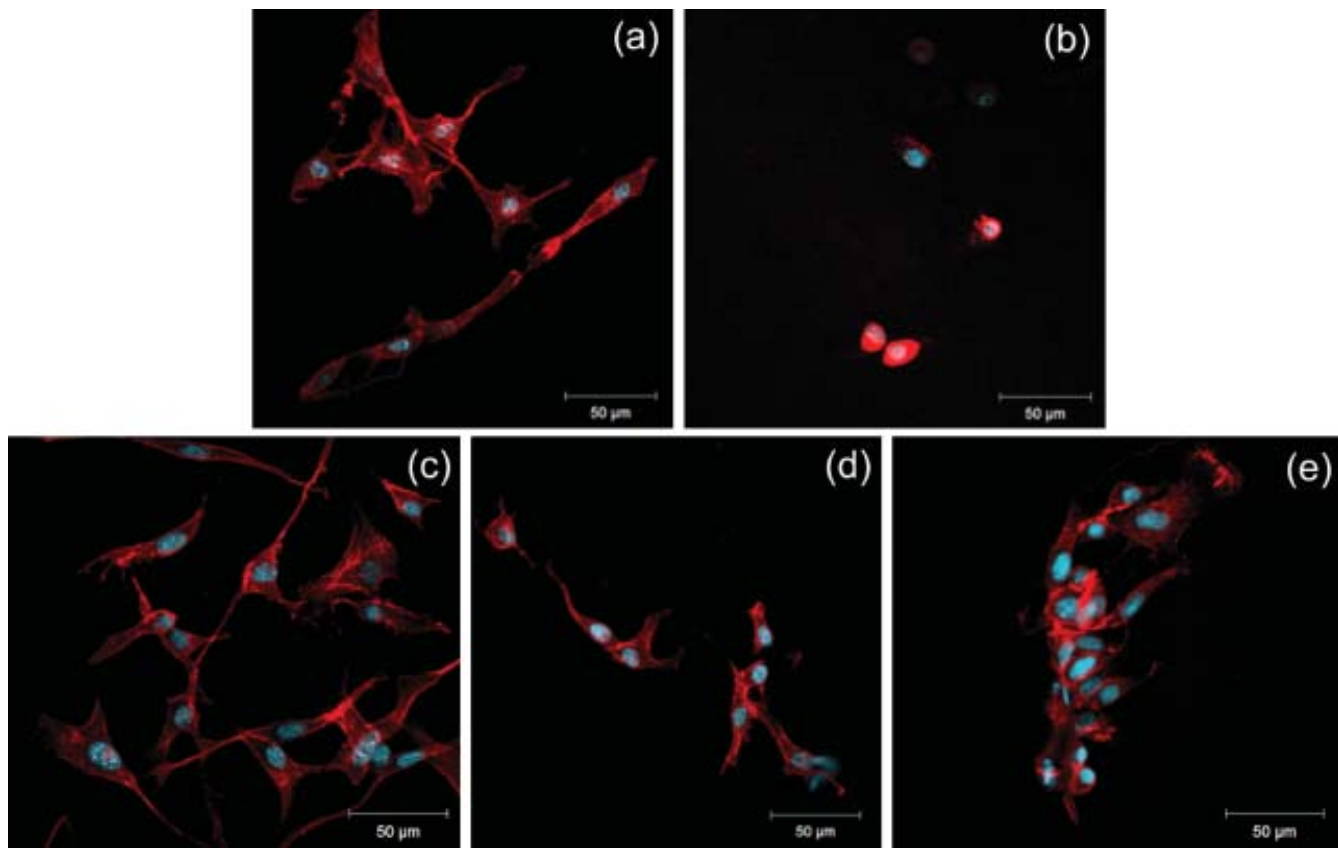

Figure 10. Confocal microscopy images of $\mathrm{NIH}_{3} \mathrm{~T}_{3}$ murine fibroblasts grown on a) poly(L-lysine)-coated cover slip, b) PVC film, c) PPX-CH $\mathrm{NH}_{2}$, d) 1: 1 ratio of $\mathrm{PPX}-\mathrm{CH}_{2} \mathrm{NH}_{2}$ and PPX-COCF , and e) PPX- $-\mathrm{COCF}_{3}$ surfaces. Red: actin cytoskeleton (rhodamine-phalloidin), blue: nucleus (DAPI). $n=3$, representative images shown. All scale bars are $50 \mu \mathrm{m}$.

(a)<smiles>[R]C(=O)c1cc(C)ccc1C</smiles>

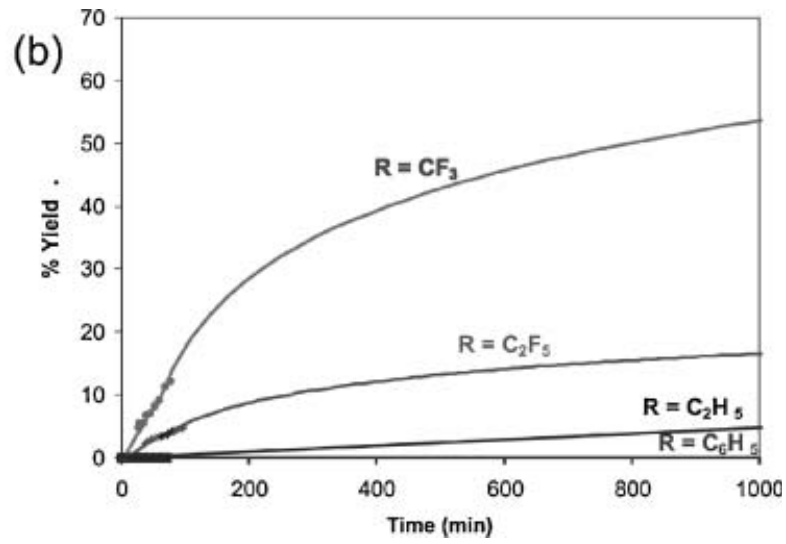

Figure 11. a) Protocol used to determine the reaction kinetics of different carbonyl-PPXs, using functionalized $p$-xylenes as test molecules. b) Percentage yield of carbonyl reactions with respect to time, based upon ${ }^{1} \mathrm{H}$ NMR analysis of characteristic reactant/product peaks.

\section{Conclusion}

We have demonstrated the versatility and activity of carbonyl-functionalized PPXs polymerized from functionalized PCPs. Compositions of these polymers, both within the bulk coating and at the surface, were verified by FT-IR spectroscopy and XPS. The carbonyl-functionalized polymers also exhibit drastic differences in crystallinity, which can be attributed to compositional changes of the functional group. These subtle changes also result in altered cellular morphologies on surfaces coated with the CVD polymers.

In addition, we also copolymerized carbonyl-functionalized paracyclophanes with amine-functionalized molecules. The resulting copolymers possessed mechanical integrity and were dually reactive through the presence of amine and carbonyl groups. FT-IR spectra illustrated the control of the copolymer compositions, which were relatively homogeneous over several inches. We also observed that the copolymer composition is directly 

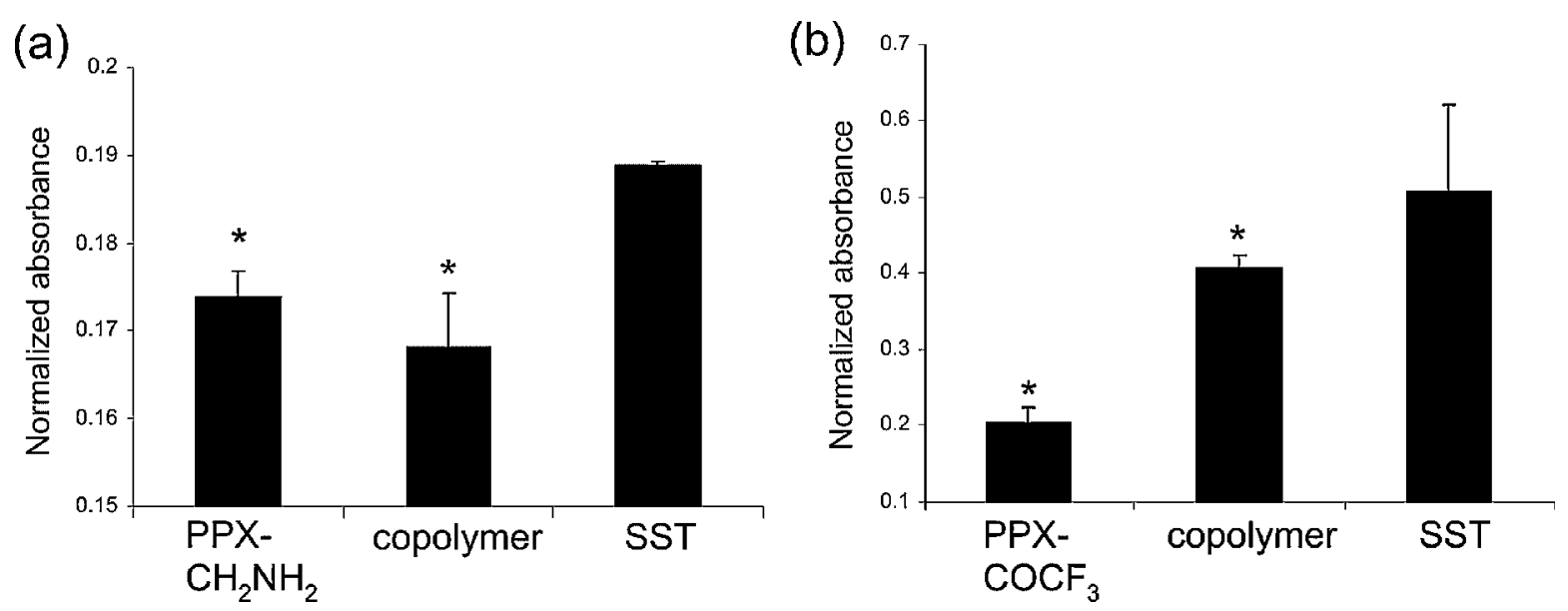

Figure 12. a) Hirudin binding as measured by chromogenic assay. Normalized absorbance at $405 \mathrm{~nm}$ are reported. $n=3,{ }^{*}: p<0.05$ compared to stainless steel. b) Heparin binding as measured by toluidine blue absorbance. Normalized absorbance at $631 \mathrm{~nm}$ is reported. $n=3,{ }^{*}$ : $p<0.05$ compared to stainless steel.

related to the monomer sublimation temperatures, where changing the sublimation temperature(s) affected relative sublimation rates. These copolymers showed potential use as biomedical coatings as determined by protein adsorption, cell adhesion, biocompatibility, and immobilization of model drugs.

For the CVD polymerization to be successful, initiation and propagation steps must be conducive to producing robust, functional polymer coatings. Less than optimum polymer films will result if, for example, monomer pyrolysis is incomplete. These effects apply to CVD polymerization in general, but are even more pronounced for the case of CVD copolymerization. For the polymer combinations used herein, we optimized parameters to yield controlled polymer compositions. However, optimization must be performed on a case-by-case basis and limitations with respect to obtainable CVD copolymers as novel CVD coatings will need to be explored.

Acknowledgements: JL gratefully acknowledges support from the NSF in form of a CAREER grant (DMR-0449462) and Major Instrumentation Grant (DMR-0420785). YE gratefully acknowledges support from an NIH/NIBIB training grant $(5$ T32 EB005582-02). The authors also thank Dr. Russell Taichman and Dr. Nick Kotov for use of the fluorescence plate reader and UV spectrometer, respectively. Confocal microscopy was performed at UM Microscopy and Image Analysis Laboratory.

Received: February 18, 2008; Revised: April 2, 2008; Accepted: April 2, 2008; DOI: 10.1002/marc.200800101

Keywords: biomaterials; chemical vapor deposition; coatings; immobilization; surface analysis

[1] A. Chilkoti, J. A. Hubbell, MRS Bull. 2005, 30, 175.

[2] R. Langer, D. A. Tirrell, Nature 2004, 428, 487.

[3] M. Mrksich, MRS Bull. 2005, 30, 180.
[4] [4a] P. S. Dittrich, K. Tachikawa, A. Manz, Anal. Chem. 2006, 78, 3887; [4b] D. R. Reyes, D. Iossifidis, P. A. Auroux, A. Manz, Anal. Chem 2002, 74, 2623.

[5] H. J. Chung, T. G. Park, Adv. Drug Delivery Rev. 2007, 59, 249.

[6] W. J. Kao, Biomaterials 1999, 20, 2213.

[7] M. B. Gorbet, M. V. Sefton, Biomaterials 2004, 25, 5681.

[8] B. D. Ratner, A. S. Hoffman, F. J. Schoen, J. E. Lemons, "Biomaterials Science", 2nd edition, Elsevier Inc., Dordrecht, The Netherlands 2004, pp. 332-338.

[9] [9a] M. Yoshida, R. Langer, A. Lendlein, J. Lahann, Poly. Rev. 2006, 46, 347; [9b] D. J. Mooney, E. A. Silva, Nat. Mater. 2007, $6,327$.

[10] F. F. Shi, Surf. Coatings Technol. 1996, 82, 1.

[11] [11a] R. G. Nuzzo, D. L. Allara, J. Am. Chem. Soc. 1983, 105, 4481; [11b] S. Onclin, B. J. Ravoo, D. N. Reinhoudt, Angew. Chem. Int. Ed. 2005, 44, 6282.

[12] M. Chen, H. Liang, Y. Chiu, Y. Chang, H. Wei, H. Sung, J. Controlled Release 2005, 108, 178.

[13] B. D. Ratner, A. S. Hoffman, F. J. Schoen, J. E. Lemons, "Biomaterials Science", 2nd edition, Elsevier Inc., Dordrecht, The Netherlands 2004, p. 1-3.

[14] G. Mani, M. D. Feldman, D. Patel, C. M. Agrawal, Biomaterials 2007, 28, 1689.

[15] S. D. Senturia, "Microsystem Design", Kluwer Academic Publishers, Dordrecht, The Netherlands 2000.

[16] [16a] Y. C. Chang, C. W. Frank, Langmuir 1998, 14, 326; [16b] N. H. Lee, C. W. Frank, Langmuir 2003, 19, 1295.

[17] [17a] Y. Mao, K. K. Gleason, Langmuir 2004, 20, 2484; [17b] T. P. Martin, K. K. Gleason, Chem. Vap. Dep. 2006, 12, 685.

[18] W. S. O'Shaughnessy, S. Baxamusa, K. K. Gleason, Chem. Mater. 2007, 19, 5836.

[19] W. F. Gorham, J. Polym. Sci., Part A 1966, 4, 3027.

[20] [20a] J. Lahann, R. Langer, Macromolecules 2002, 35, 4380; [20b] H. Nandivada, H. Y. Chen, L. Bondarenko, J. Lahann, Angew. Chem. Int. Ed. 2006, 45, 3360; [20c] X. Jiang, H. Y. Chen, G. Galvan, M. Yoshida, J. Lahann, Adv. Func. Mater. 2008, 18, 27; [20d] J. Lahann, M. Balcells, T. Rodon, J. Lee, I. S. Choi, K. F. Jensen, R. Langer, Langmuir 2002, 18, 3632; [20e] J. Lahann, R. Langer, Macromol. Rapid Commun. 2001, 22, 968.

[21] [21a] M. Morgen, S. H. Rhee, J. H. Zhao, I. Malik, T. Ryan, H. M. Ho, M. A. Plano, P. Ho, Macromolecules 1999, 32, 7555; [21b] J. J. Senkevich, S. B. Desu, V. Simkovic, Polymer 2000, 41, 2379; [21c] S. Y. Park, S. N. Chvalun, A. A. Nikolaev, K. A. Mailyan, 
A. V. Pebalk, I. E. Kardash, Polymer 2000, 41, 2937; [21d] D. Klee, N. Weiss, J. Lahann, "Vapor-Based Polymerization of Functionalized [2. 2]Paracyclophanes: A Unique Approach towards Surface-Engineered Microenvironments", in: Modern Cyclophane Chemistry, Wiley-VCH, Weinheim 2004, Ch. 18, p. 463.

[22] [22a] K. Y. Suh, R. Langer, J. Lahann, Adv. Mater. 2004, 16, 1401;[22b] H. Y. Chen, J. Lahann, Anal. Chem. 2005, 77, 6909.

[23] H. Nandivada, H. Y. Chen, J. Lahann, Macromol. Rapid Commun. 2005, 26, 1794.

[24] L. K. Keefer, Nat. Mater. 2003, 2, 357.

[25] D. G. Castner, B. D. Ratner, Surf. Sci. 2002, 500, 28.

[26] Y. Elkasabi, H. Y. Chen, J. Lahann, Adv. Mater. 2006, 18, 1521.

[27] J. Lahann, H. Hocker, R. Langer, Angew. Chem. Int. Ed. 2001, 40, 726.

[28] J. Lahann, Polym. Int. 2006, 55, 1361.

[29] J. Lahann, W. Plüster, T. Rodon, M. Fabry, D. Klee, H.-G. Gattner, H. Höcker, Macromol. Biosci. 2002, 2, 82.

[30] [30a] P. Simon, S. Mang, A. Hasenhindl, W. Gronski, A. Greiner, Macromolecules 1998, 31, 8775; [30b] C. Schmidt, V. Stuempflen, J. Wendorff, A. Hasenhindl, W. Gronski, M. Ishaque, A. Greiner, Acta Polym. 1998, 49, 232; [30c] L. You, G. Yang, C.
Lang, P. Wu, J. Moore, J. McDonald, T. M. Lu, J. Vac. Sci. Technol. A 1993, 11, 3047.

[31] H. Y. Chen, J. M. Rouillard, E. Gulari, J. Lahann, Proc. Natl. Acad. Sci. USA 2007, 104, 11173.

[32] [32a] H. Y. Chen, J. Lahann, Adv. Mater. 2007, 19, 3801; [32b] S. Thévenet, H.-Y. Chen, J. Lahann, F. Stellacci, Adv. Mater. 2007, 19, 4333.

[33] J. Lahann, D. Klee, H. Hocker, Macromol. Rapid Commun. 1998, 19, 441

[34] [34a] D. R. Critchley, Biochem. Soc. Trans. 2004, 32, 831; [34b] E. Zamir, B. Geiger, J. Cell Sci. 2001, 114, 3583.

[35] J. A. Gardella, S. A. Ferguson, R. L. Chin, Appl. Spectrosc. 1986, 40, 224.

[36] S. Beguin, R. Kumar, Thromb. Haemost. 1997, 78, 590.

[37] Z. Zhang, K. Apse, J. Pang, R. C. Stanton, J. Biol. Chem. 2000, 275,40042

[38] J. F. Schmedtje, Jr., M. S. Runge, D. Baykal, Am. J. Cardiol. 1995, $75,82 \mathrm{~B}$.

[39] J. Lahann, D. Klee, W. Pluester, H. Hoecker, Biomaterials 2001, 22, 817.

[40] H. Chen, Y. Chen, H. Sheardown, M. A. Brook, Biomaterials 2005, 26, 7418 